\title{
3 Research Square

\section{The Experimental Study on Interaction of Vibration and Dynamic Force in Precision Milling Process}

\author{
Weicheng Guo \\ University of Shanghai for Science and Technology \\ Miaoxian Guo ( $\nabla$ miaoxian.guo@live.com ) \\ University of Shanghai for Science and Technology \\ Yi Ye \\ University of Shanghai for Science and Technology \\ Xiaohui Jiang \\ University of Shanghai for Science and Technology \\ Chongjun Wu \\ Donghua University
}

\section{Research Article}

Keywords: Milling, Vibration interaction, Dynamic force, PMI

Posted Date: August 30th, 2021

DOI: https://doi.org/10.21203/rs.3.rs-843453/v1

License: (c) (1) This work is licensed under a Creative Commons Attribution 4.0 International License. Read Full License

Version of Record: A version of this preprint was published at The International Journal of Advanced Manufacturing Technology on January 28th, 2022. See the published version at https://doi.org/10.1007/s00170-021-08568-0. 


\section{The experimental study on interaction of vibration and dynamic force in precision milling process}

\section{Weicheng Guo}

School of Mechanical Engineering,

University of Shanghai for Science and Technology,

No. 516 Jungong Rd, 200093, Yangpu, Shanghai, China

e-mail:wcguo@usst.edu.cn

\section{Miaoxian Guo*}

School of Mechanical Engineering,

University of Shanghai for Science and Technology, No. 516 Jungong Rd,

200093, Yangpu, Shanghai, China

e-mail: guomx@usst.edu.cn

Yi Ye

School of Mechanical Engineering,

University of Shanghai for Science and Technology, No. 516 Jungong Rd,

200093, Yangpu, Shanghai, China

e-mail: 13584763276@163.com

\section{Xiaohui Jiang}

School of Mechanical Engineering,

University of Shanghai for Science and Technology,

No. 516 Jungong Rd,

200093, Yangpu, Shanghai, China

e-mail: jiangxh@usst.edu.cn

\section{Chongjun Wu}

School of Mechanical Engineering,

Donghua University,

No. 2999 Renmin Rd,

201620, Songjiang, Shanghai, China

e-mail: wcjunm@dhu.edu.cn

* Corresponding author. 


\section{ABSTRACT}

A good understanding of the dynamic characteristic in milling of aerospace aluminum, especially the coupling vibration caused by the interaction of the manufacturing process and the machine tool, helps promote the machining precision and surface quality of aerospace structural components. This paper is devoted to proposing the interaction theory of the vibration and dynamic force, which is verified in the milling of $\mathrm{Al} \mathrm{7075-T651} \mathrm{by} \mathrm{consideration} \mathrm{both} \mathrm{the} \mathrm{machine} \mathrm{tool} \mathrm{load} \mathrm{and} \mathrm{machining} \mathrm{process}$ dynamic load. First, through detailed analysis of the interaction effect of vibration and the dynamic force, the dynamic milling process is simplified to theoretically model the dynamic interaction in the precision manufacturing process under non-chatter condition. Then, the dynamic process force, which is the key source of the interaction, is modeled and obtained based on wavelet packet transform preprocess; the Frequency Response Function (FRF) of machine tool is regarded as the interaction link between the dynamic force load and the vibration response; the machine tool non-cutting vibration is transformed as a special dynamic load superposed on the response. Finally, the interaction vibration is calculated applying interaction effect model, the predicated results obtained in interaction effect approach match well with the vibration signal directly obtained in the test.

\section{Keywords}

Milling; Vibration interaction; Dynamic force; PMI

\section{INTRODUCTION}

Precision milling process has been widely applied in the manufacturing of Al-based structural parts for aerospace applications, such as manned space stations, deep space explorers and highperformance satellites. However, the dimension accuracy and surface performance of the parts cannot be precisely controlled in many cases, and thus, the stable operation of aerospace equipment cannot be guaranteed. One of the most critical problems limiting the performance of precision milling parts is the coupled vibration caused by the dynamic load interaction of the manufacturing process and the machine tool. The complex dynamic characteristics in the milling process results in an in-depth understanding of the synthetically interaction of the vibrations induced by the manufacturing process and the machine tool. Previous studies in the literature have generally focused on the experimentaltheoretical investigation of machine tool vibration and milling process dynamics without engaging in a thorough analysis of the Process and Machine Interaction (PMI) [1-2]. 
In some cases, most of the research works focus on the spindle and tool vibration. The vibration in precision milling would result in the periodic variation of the relative displacement between tool and workpiece and affect the surface generation in process [3]. Filiz et al. [4] developed analytical models for the dynamics of micro-scale cutting-tools and experimental models for an ultra-high-speed spindle. Zhang et al. [5-6] developed a specialized model for an aerostatic bearing spindle under impulsive excitation from intermittent cutting forces of ultra-precision raster milling to analyze the effects of the particular spindle vibration on surface generation. They found that the phase shift is a key factor influencing the surface patterns. To further determine the influence of spindle vibration on the machining surface, Ma et al. [7] investigated the effect of the geometric feature of a curved surface and the cutting direction along the tool path on the variation of force and vibration in high-speed milling. Jiang et al. [8] built a three-dimensional model of machined surface topography in simulation to analyze the influence of tool wear and vibration on the spatial trajectory of the knife tip. They concluded that axis amplitude is a key factor affecting surface residual height. These works show that the vibration load of machine tools has a significant impact on precision machining, but the research mainly focuses on the vibration of the machine tool.

As in the milling process, the vibrations include three parts: free vibration, forced vibration, and self-excited vibration (chatter). Generally, chatter occurs when the excitation frequency in cutting is equal or close to one of the natural frequencies of the machine tool, referred to as instable cutting [9]. Chatter behavior depends upon a number of different aspects including spindle speeds, material properties, tool geometry, and even the location of tool respect to the rest of machine [10]. However, when the depth of the cut is small in precision milling, the influence of chatter vibration can possibly be disregarded [11]. Therefore, the forced vibration of the cutting process is the main factor in stability precision milling. In some studies, the process force is limited in the static field to investigate deformation mechanism, surface integrity, and microscopic features [12-15]. A new basis for modeling dynamic forces from the static component and harmonic contributions is presented, as modeling the dynamic high speed milling force signal accounts for secondary harmonics [16]. Moradi et al. developed an extended dynamic model of a peripheral milling process including process damping and structural and cutting force nonlinearities using experimental coefficients [17].

Furthermore, combining the dynamic force and vibration response, Jalili et al. [18] studied the influences of the axial depth of cut, cutting tool diameter, cutting tool length, and number of cutter 
teeth on the frequency response of the tool tip vibrations using a 3-D nonlinear dynamic model of the milling process. Jiang et al. [19] found a larger tool radius and a smaller cutting depth can control the vibration of curved thin-walled part. Wang et al. [20] proposed a cutting force prediction algorithm considering the influence of cutter vibrations and cutter run-out. Albertelli et al. [21] designed an inprocess model-based estimator of cutting forces and tool-tip vibration based on both a machine dynamic model and indirect measurements coming from multiple sensors placed in the machine. Grossi et al. [22-23] found that dynamic cutting force coefficients change appreciably with spindle speed as mechanics of cutting change, and then carried out a deep investigation of cutting force coefficients to estimate the cutting force and tool-tip vibrational behavior.

The process vibration is the result of the coupling of machine-process vibration. However, limited studies in the field have focused on the interaction effect of the machine tool dynamic load and the process dynamic force. Generally in the interaction analysis, the cutting force would cause related vibration of machine, and the vibration also reacts on the cutting force due to the cutting parameters fluctuation by vibration.

In this paper, the interaction effect of milling vibration and the dynamic force is explored during the milling of Al 7075-T651. First, the dynamic milling process is simplified to theoretically study the vibration interaction model in the precision milling process. Whatever the vibration interaction sources are, they can be transformed as the dynamic load in the study. Then, the dynamic process force in process is measured and preprocess based on wavelet packet transform as the coupled force which reflects the cutting mechanism as well as the process vibration; the machine tool non-cutting vibration is regarded as another dynamic load; the Frequency Response Function (FRF) of dynamic performance is regards the interaction link between the dynamic force and the vibration response. Finally, the interaction vibration is calculated applying interaction effect model based on forced vibration and linear system assumption to verify the interaction effect model.

\section{THEORETICAL ANALYSIS}

\subsection{Interaction Effect Analysis Approach}

Based on PMI analysis as shown in Fig. 1, the process and the machine tool loads result in the unpredictable effects of interaction. The interaction of vibration to the dynamic forces of milling can include dynamic instabilities in the system, such as chatter vibrations or dynamic deflections. However, 
while the cutting depth is very small in precision stable cutting process, the vibrations with a forcedisplacement interaction between the machine tool and the cutting process is the main phenomenon.

In the process vibration-force interaction, the machine free-run vibration would bring the initial change of cutting parameters as $\triangle v_{0}, \triangle f_{0}, \triangle \alpha_{p 0}$. Then the material removal process produces dynamic cutting force and react on the process, and finally results in the stable dynamic change of cutting parameters and appears the continuous vibration and dynamic force in machining.

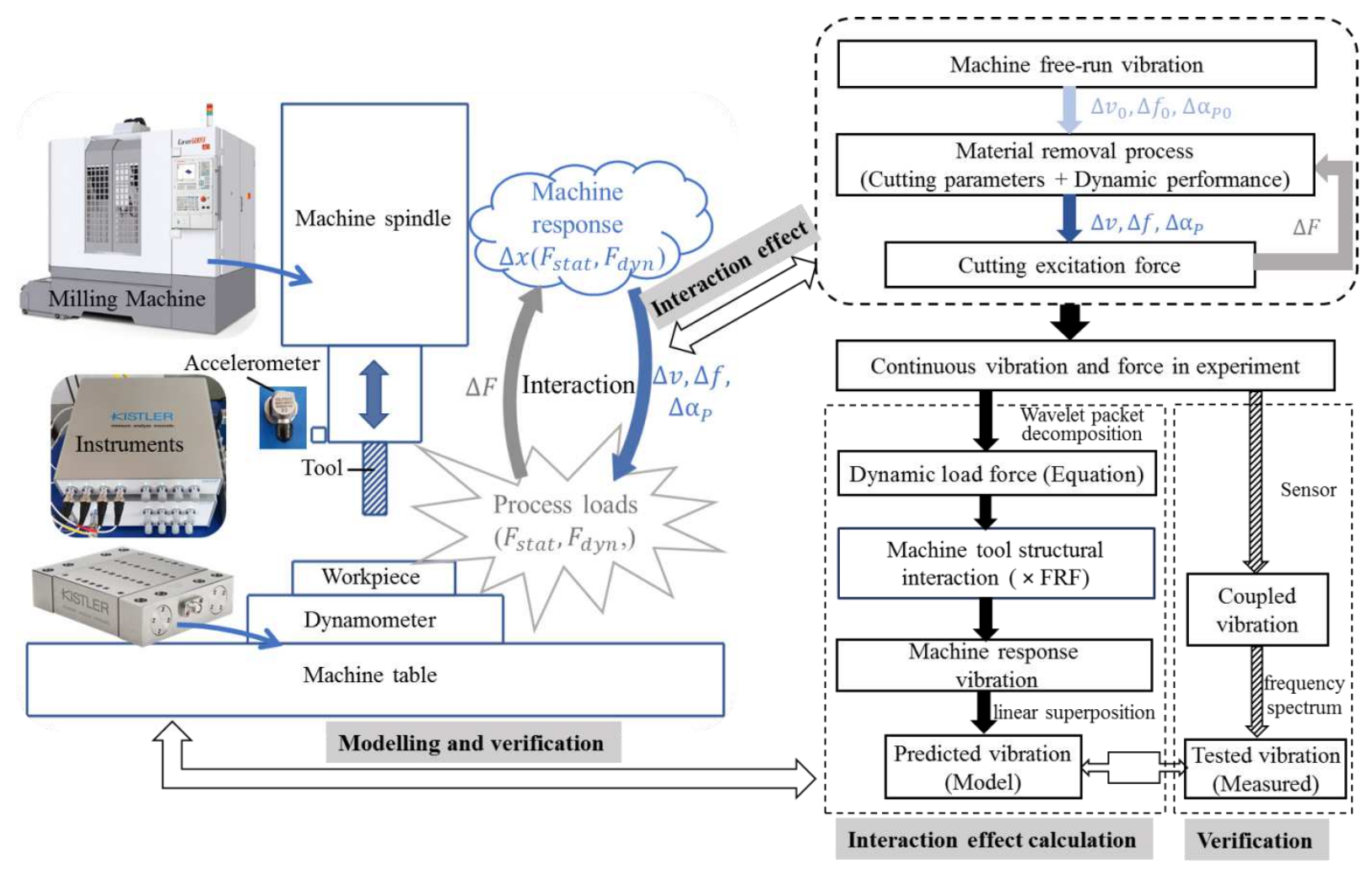

Fig. 1 Analysis of process and machine interaction

In the interaction effect calculation, the dynamic behavior is determined by impacting the machine tool with a dynamic force and measuring the response in the form of vibration. The measured FRF is applied as a relation function between cutting force load and vibration. Furthermore, the dynamic milling force in stable process is applied as the interaction source, and wavelet packet transform is applied in signal preprocessing to extract the periodic component. Finally, the millingforced vibration response is calculated according to the proposed conversion method, and the predicted interaction vibration is obtained in consideration of both free-run machine tool vibration and process forced vibration based on the linear superposition method. In the verification, the coupled vibration is tested and compared with the predicted vibration.

\subsection{Theoretical Modeling}


The dynamic milling process considering the dynamic milling force is simplified in the vibration interaction theoretical modeling. As shown in Fig. 2, the dynamic milling process is simplified as a three-degrees-of-freedom system [24-25], which is expressed in three directions (Xfeed direction, Y-perpendicular to feed direction, and Z-axial direction), the governing equation can be described as follows:

$$
[M] \ddot{S}(t)+[C] \dot{S}(t)+[K] S(t)=F(t)
$$

where

$$
F(t)=\left[F_{x}(t), F_{y}(t), F_{z}(t)\right]^{T}
$$

$F(t)$ is the milling forces vector; $\mathrm{M}, \mathrm{C}$, and $\mathrm{K}$ are the modal mass, damping, and stiffness of tool and workpiece, respectively; and $\mathrm{S}$ is the vibration displacement vector. With the subscript ' $\mathrm{m}$ ' and 'w', $M_{m}, C_{m}, K_{m}, S_{m}$ stand for the milling tool and $M_{w}, C_{w}, K_{w}, S_{w}$ stand for the workpiece.

$$
\begin{aligned}
& S_{m}(t)=\left[x_{m}(t), y_{m}(t), z_{m}(t)\right]^{T} \\
& S_{w}(t)=\left[x_{w}(t), y_{w}(t), z_{w}(t)\right]^{T}
\end{aligned}
$$

The vibration leads to dynamic change of cutting depth. Fig. 3 demonstrates the dynamic changes of cutting thickness produced by the single cutter tooth, which can be summarized as:

$$
\begin{aligned}
& \phi_{j}=(j-1) \phi_{p}+\phi \\
& \phi_{p}=2 \pi / N
\end{aligned}
$$
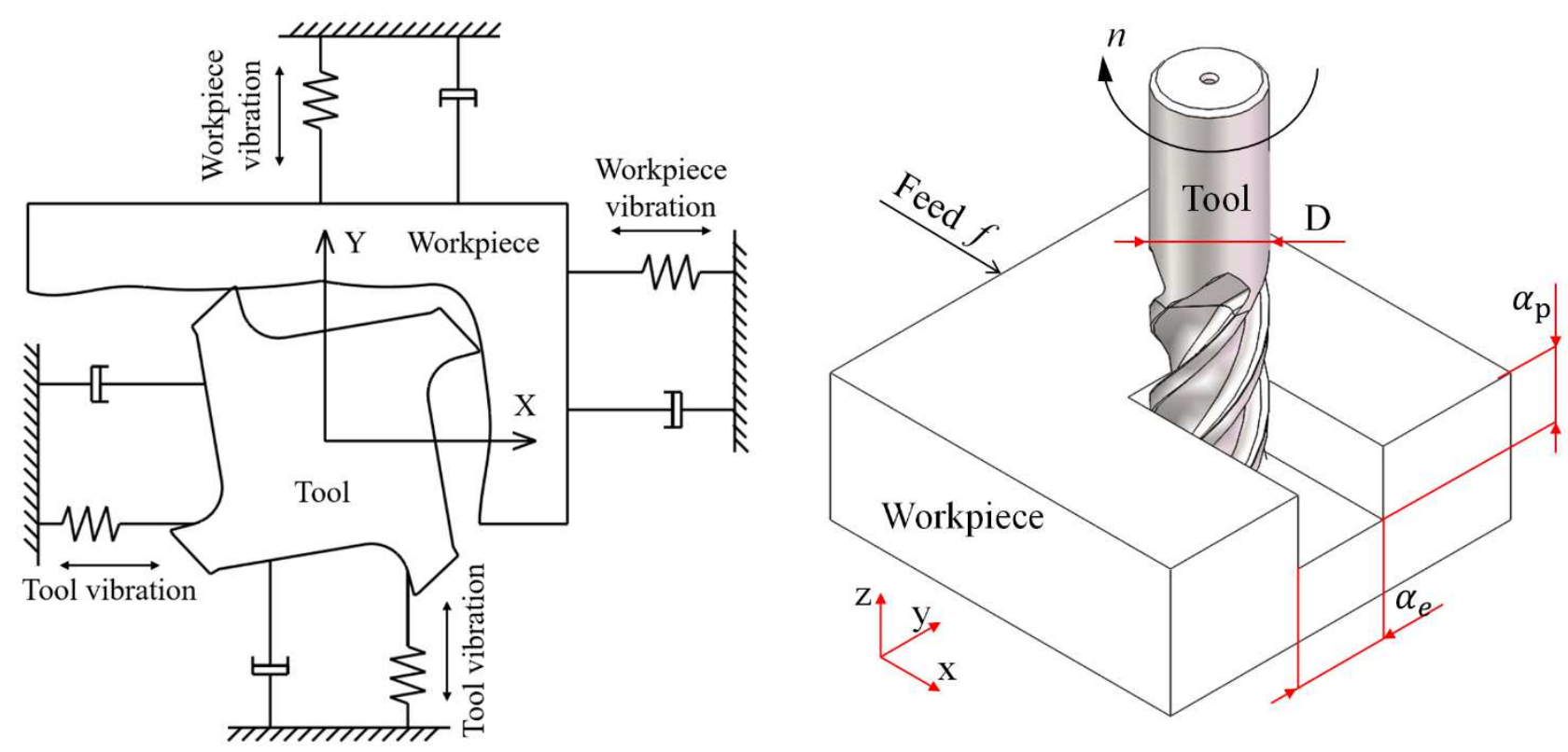


\section{Fig. 2 Schematic diagram of milling dynamics}

In which $\phi_{j}$ is the instantaneous radial contact angle of the jth cutter tooth, $\phi_{p}$ is the average circumferential angle of each cutter tooth. The total cutting thickness can be expressed by the sum of static cutting thickness and dynamic cutting thickness:

$$
h\left(\phi_{j}\right)=\left\{f_{t} \sin \phi_{j}+\Delta f_{v}\right\} g\left(\phi_{j}\right)
$$

Where $f_{t} \sin \phi_{j}$ is static cutting thickness, $f_{t}$ is the feed rate per tooth, $\Delta f_{v}$ is dynamic change of cutting depth, $\mathrm{g}\left(\phi_{j}\right)$ is milling cutter teeth participation parameter.

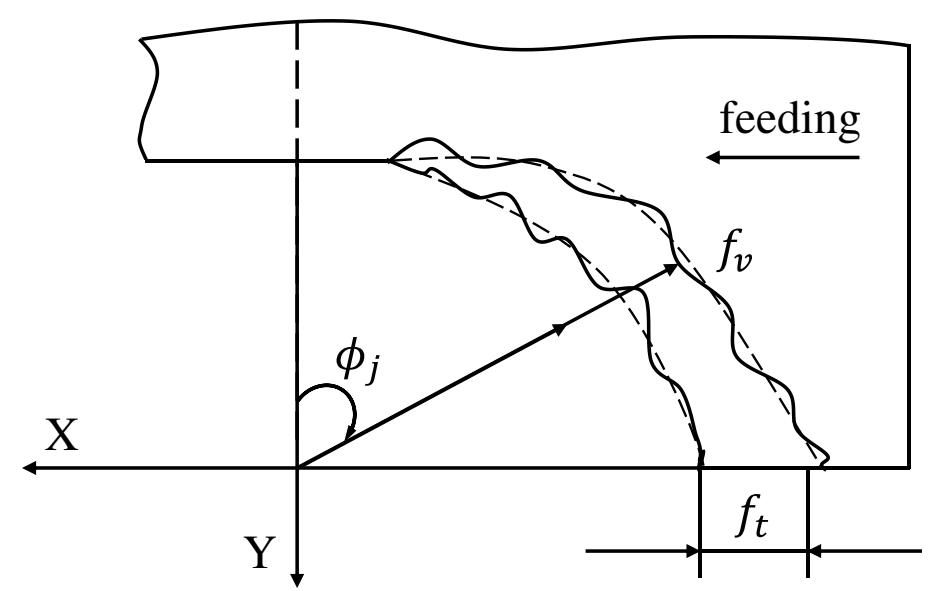

Fig. 3 Dynamic changes of cutting thickness

In the study of dynamic force, only its dynamic change is considered,

$$
h\left(\phi_{j}\right)=\Delta x \sin \phi_{j}+\Delta y \cos \phi_{j}
$$

where $\Delta x=\Delta x_{m}-\Delta x_{w}, \Delta y=\Delta y_{m}-\Delta y_{w}, \Delta z=\Delta z_{m}-\Delta z_{w}$ are the dynamic changes in the directions.

The tangential, the radial dynamic cutting forces and the axial cutting force can be expressed as:

$$
\begin{aligned}
& F_{t j}=K_{t c} a_{p} h\left(\phi_{j}\right) \\
& F_{r j}=K_{r} F_{t j} \\
& F_{z j}=F_{a j}=K_{a c} \Delta a_{p j} f_{t}
\end{aligned}
$$

$a_{p}$ is the axial cutting depth; $K_{r}=\frac{K_{r c}}{K_{t c}}, K_{r c}$ is the coefficient of radial force, $K_{t c}$ is the tangential force coefficient. Then

$$
F_{x j}=-F_{t j} \cos \phi_{j}-F_{r j} \sin \phi_{j}
$$




$$
F_{y j}=+F_{t j} \sin \phi_{j}-F_{r j} \cos \phi_{j}
$$

The total cutting force is:

$$
\begin{aligned}
& F_{x}=\sum_{j=0}^{N-1} F_{x j}\left(\phi_{j}\right) \\
& F_{y}=\sum_{j=0}^{N-1} F_{y j}\left(\phi_{j}\right) \\
& F_{z}=\sum_{j=0}^{N-1} F_{a j}
\end{aligned}
$$

Therefore, the cutting force can be expressed as:

$$
\begin{aligned}
& \left(\begin{array}{l}
F_{x} \\
F_{y} \\
F_{z}
\end{array}\right)=\frac{1}{2} a_{p} K_{t c}\left[\begin{array}{ccc}
\alpha_{x x} & \alpha_{x y} & 0 \\
\alpha_{y x} & \alpha_{y y} & 0 \\
0 & 0 & \frac{2 K_{a c} \Delta a_{p j}}{a_{p} K_{t c}}
\end{array}\right]\left(\begin{array}{l}
\Delta_{x} \\
\Delta_{y} \\
\Delta_{z}
\end{array}\right) \\
& \alpha_{x x}=\sum_{j=0}^{N-1}-g_{j}\left[\sin 2 \phi_{j}+K_{r}\left(1-\cos 2 \phi_{j}\right)\right] \\
& \alpha_{x y}=\sum_{j=0}^{N-1}-g_{j}\left[\left(1+\cos 2 \phi_{j}\right)+K_{r} \sin 2 \phi_{j}\right] \\
& \alpha_{y x}=\sum_{j=0}^{N-1} g_{j}\left[\left(1-\cos 2 \phi_{j}\right)+K_{r} \sin 2 \phi_{j}\right] \\
& \alpha_{y y}=\sum_{j=0}^{N-1} g_{j}\left[\sin 2 \phi_{j}-K_{r}\left(1+\cos 2 \phi_{j}\right)\right]
\end{aligned}
$$

By means of discretization, Eq. (17) can be expressed in matrix form in time domain:

$$
[F(\tau)]=\frac{1}{2} a_{p} K_{t c}[A(\tau)][\Delta(\tau)]
$$

Where $A(\tau)$ is the periodic function with angular frequency $\omega,[\Delta(\tau)]$ is the dynamic displacement vector.

In frequency domain, the periodic function in milling force can be expanded as follows:

$$
\begin{aligned}
{[A(\tau)] } & =\sum_{r=-\infty}^{\infty}\left[A_{r}\right] e^{i r \omega t} \\
{\left[A_{r}\right] } & =\frac{1}{T} \int_{0}^{T}[A(\tau)] e^{-i r \omega \tau} d \tau
\end{aligned}
$$

For both the milling machine tool and the workpiece, the dynamic milling force would excite the continuously vibration. Taking one direction as an example, the response of milling force excitation can be calculated through the Duhamel integral as follows [26]:

$$
x(t)=\frac{1}{m \omega_{d}} \int_{0}^{t} F(\tau) e^{-\varepsilon \omega_{n}(t-\tau)} \sin \omega_{d}(t-\tau) d \tau+e^{-\varepsilon \omega_{n} t}\left(x_{0} \cos \omega_{d} t+\frac{\dot{x}_{0}+\varepsilon \omega_{n} x_{0}}{\omega_{d}} \sin \omega_{d}\right)
$$

When the initial displacement $x_{0}$ and the initial velocity $\dot{x}_{0}$ is zero, Eq. (25) can be omitted:

$$
x(t)=\frac{1}{m \omega_{d}} \int_{0}^{t} F(\tau) e^{-\varepsilon \omega_{n}(t-\tau)} \sin \omega_{d}(t-\tau) d \tau=\int_{0}^{t} h_{x x}(t-\tau) F(\tau) d \tau
$$


Therefore, the response can be calculated under the linear system assumption as follows:

$$
\left[\begin{array}{l}
x(t) \\
y(t) \\
z(t)
\end{array}\right]=\left[\begin{array}{l}
\int_{0}^{t} h_{x x}(t-\tau) F_{x}(\tau) d \tau+\int_{0}^{t} h_{x y}(t-\tau) F_{y}(\tau) d \tau+\int_{0}^{t} h_{x z}(t-\tau) F_{z}(\tau) d \tau \\
\int_{0}^{t} h_{y x}(t-\tau) F_{x}(\tau) d \tau+\int_{0}^{t} h_{y y}(t-\tau) F_{y}(\tau) d \tau+\int_{0}^{t} h_{y z}(t-\tau) F_{z}(\tau) d \tau \\
\int_{0}^{t} h_{z x}(t-\tau) F_{x}(\tau) d \tau+\int_{0}^{t} h_{z y}(t-\tau) F_{y}(\tau) d \tau+\int_{0}^{t} h_{z z}(t-\tau) F_{z}(\tau) d \tau
\end{array}\right]
$$

The vibration analysis above is based on the cutting force excited vibration in milling under non-chatter condition. Furthermore, the machine tool vibration in the system should also be considered, thus Eq. (27) can be extended to the study of milling vibration with the mechanical vibration superposition principle.

$$
\left[\begin{array}{l}
x_{m}(t) \\
y_{m}(t) \\
z_{m}(t)
\end{array}\right]=\left[\begin{array}{l}
\int_{0}^{t} h_{m x x}(t-\tau) F_{x}(\tau) d \tau+\int_{0}^{t} h_{m x y}(t-\tau) F_{y}(\tau) d \tau+\int_{0}^{t} h_{m x z}(t-\tau) F_{z}(\tau) d \tau \\
\int_{0}^{t} h_{m y x}(t-\tau) F_{x}(\tau) d \tau+\int_{0}^{t} h_{m y y}(t-\tau) F_{y}(\tau) d \tau+\int_{0}^{t} h_{m y z}(t-\tau) F_{z}(\tau) d \tau \\
\int_{0}^{t} h_{m z x}(t-\tau) F_{x}(\tau) d \tau+\int_{0}^{t} h_{m z y}(t-\tau) F_{y}(\tau) d \tau+\int_{0}^{t} h_{m z z}(t-\tau) F_{z}(\tau) d \tau
\end{array}\right]+\left[\begin{array}{l}
x_{m 0}(t) \\
y_{m 0}(t) \\
z_{m 0}(t)
\end{array}\right]
$$

For workpiece vibration,

$$
\left[\begin{array}{l}
x_{w}(t) \\
y_{w}(t) \\
z_{w}(t)
\end{array}\right]=\left[\begin{array}{l}
\int_{0}^{t} h_{w x x}(t-\tau) F_{x}(\tau) d \tau+\int_{0}^{t} h_{w x y}(t-\tau) F_{y}(\tau) d \tau+\int_{0}^{t} h_{w x z}(t-\tau) F_{z}(\tau) d \tau \\
\int_{0}^{t} h_{w y x}(t-\tau) F_{x}(\tau) d \tau+\int_{0}^{t} h_{w y y}(t-\tau) F_{y}(\tau) d \tau+\int_{0}^{t} h_{w y z}(t-\tau) F_{z}(\tau) d \tau \\
\int_{0}^{t} h_{w z x}(t-\tau) F_{x}(\tau) d \tau+\int_{0}^{t} h_{w z y}(t-\tau) F_{y}(\tau) d \tau+\int_{0}^{t} h_{w z z}(t-\tau) F_{z}(\tau) d \tau
\end{array}\right]
$$

\section{EXPERIMENTAL SETUP}

To verify the theoretical model based on interaction effect analysis, the milling experiments are conducted on the milling machine (Model XR1000), as shown in Fig. 4. The milling forces are measured by a Kistler Force Dynamometer (Type 9139AA) mounted at the machine bed, and the vibration accelerations of the machine tool and workpiece in $\mathrm{X}$ and $\mathrm{Y}$ directions are obtained by two Kistler Annular Ceramic Shear Tri-axial Accelerometers (Type 8763B). In the test, cutting vibration along the $\mathrm{Z}$ direction is regarded having little effect on this direction due to the rigidity of the system. Therefore, this paper mainly studies the vibration of the spindle and workpiece along the $\mathrm{X}$ and $\mathrm{Y}$ directions. The signals of forces and vibrations are recorded before (free-run), during and after steadystate milling with a Kistler Instrument (Type 5165 and 5167). The impact testing is conducted with a PCB hammer (model 086C04) to analysis the frequency response functions. 


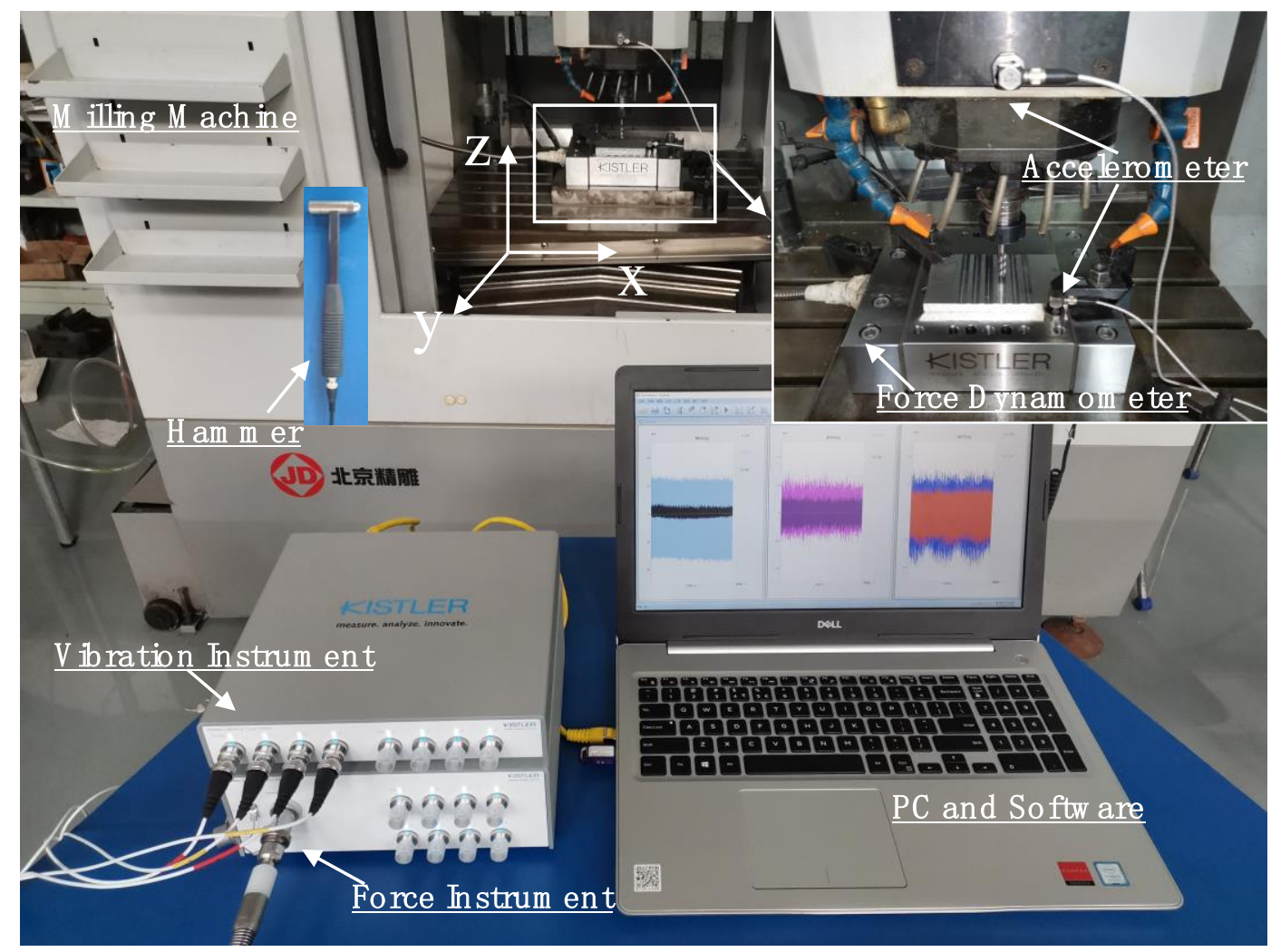

Fig. 4 Experimental setup

In the experiments, the aluminum alloy (7075-T651) workpieces with a size of $125 \times 75 \times 10$ $\mathrm{mm}$ is applied. The particular alloy is widely used in the aerospace industry and has the following chemical composition: $\mathrm{Al} 89.655 \%, \mathrm{Cu} 1.533 \%, \mathrm{Cr} 0.199 \%, \mathrm{Fe} 0.397 \%, \mathrm{Mg} 2.333 \%, \mathrm{Mn} 0.083 \%, \mathrm{Si}$

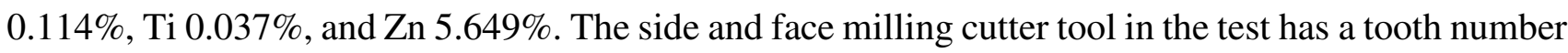
of 3 , a diameter of $8.0 \mathrm{~mm}$, a rake angle of $15^{\circ}$, a clearance angle of $6^{\circ}$, and a helix angle of $55^{\circ}$. Table 1 shows the cutting parameters of the orthogonal experiments. A straight groove is machined for each milling process, and the $\mathrm{Y}$ direction of the machine tool is selected as the feed direction.

Table 1 Milling experiments parameters

\begin{tabular}{cccc}
\hline \multirow{2}{*}{ Exp. no. } & \multicolumn{3}{c}{ Factors } \\
\cline { 2 - 4 } & Spindle speed $n(\mathrm{r} / \mathrm{min})$ & Feed rate $f(\mathrm{~m} / \mathrm{min})$ & Axial cutting depth $\alpha_{p}(\mathrm{~mm})$ \\
\hline 1 & 8000 & 0.4 & 0.3 \\
2 & 8000 & 0.6 & 0.4 \\
3 & 8000 & 0.8 & 0.5 \\
4 & 10000 & 0.4 & 0.4 \\
5 & 10000 & 0.6 & 0.5 \\
6 & 10000 & 0.8 & 0.3 \\
7 & 12000 & 0.4 & 0.5 \\
8 & 12000 & 0.6 & 0.3 \\
9 & 12000 & 0.8 & 0.4 \\
\hline
\end{tabular}




\section{RESULTS AND DISCUSSIONS}

\subsection{Frequency Response Functions of the Spindle and Workpiece}

Prior to the cutting experiments, the FRFs of the spindle and workpiece in $\mathrm{X}, \mathrm{Y}$, and $\mathrm{Z}$ directions are obtained by impacting the tool point and the workpiece cutting position, respectively. The analysis bandwidth is $1250 \mathrm{~Hz}$, and the frequency resolution is $1 \mathrm{~Hz}$ during experiments. The results are shown in Fig. 5, which illustrates the vibration resistance ability in the cutting process. The FRFs are regards as the interaction relation function between cutting excitation force and response vibration based on linear system assumption, and the dynamic exciting force is the main resource of forced vibration while there is also small self-excited vibration in process.

It can be found that the first-order natural frequencies of the tool in $\mathrm{X}, \mathrm{Y}$, and $\mathrm{Z}$ directions are about $910 \mathrm{~Hz}, 900 \mathrm{~Hz}$, and $490 \mathrm{~Hz}$, respectively, with the corresponding amplitude-frequency characteristic values $1.06 \mathrm{~g} / \mathrm{N}, 0.36 \mathrm{~g} / \mathrm{N}$, and $0.06 \mathrm{~g} / \mathrm{N}$. The first-order natural frequencies in $\mathrm{X}, \mathrm{Y}$, and $\mathrm{Z}$ directions of the workpiece are $253 \mathrm{~Hz}, 487 \mathrm{~Hz}$, and $476 \mathrm{~Hz}$, respectively, with the corresponding amplitude-frequency characteristic values $0.03 \mathrm{~g} / \mathrm{N}, 0.07 \mathrm{~g} / \mathrm{N}$, and $0.1 \mathrm{~g} / \mathrm{N}$. It is confirmed that the cutting parameters in Table 1 avoid the chatter during machining. 


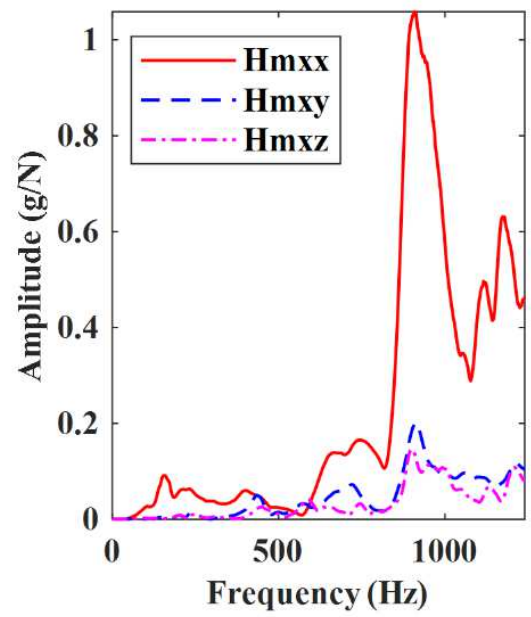

(a) Impact tool from $\mathrm{X}$-direction

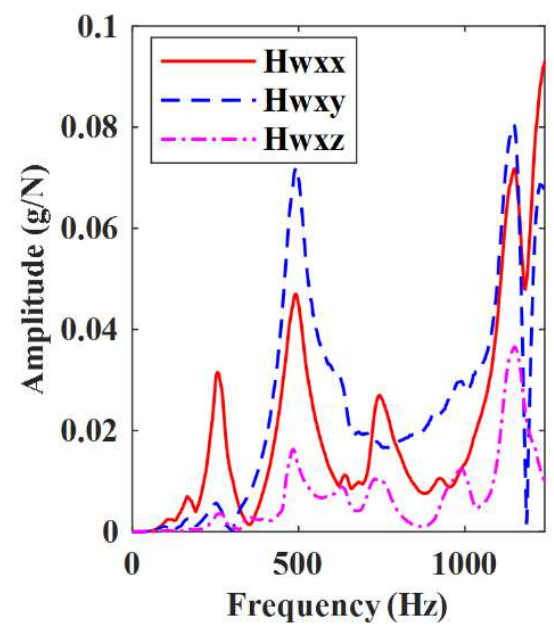

(d) Impact workpiece from $\mathrm{X}$-direction

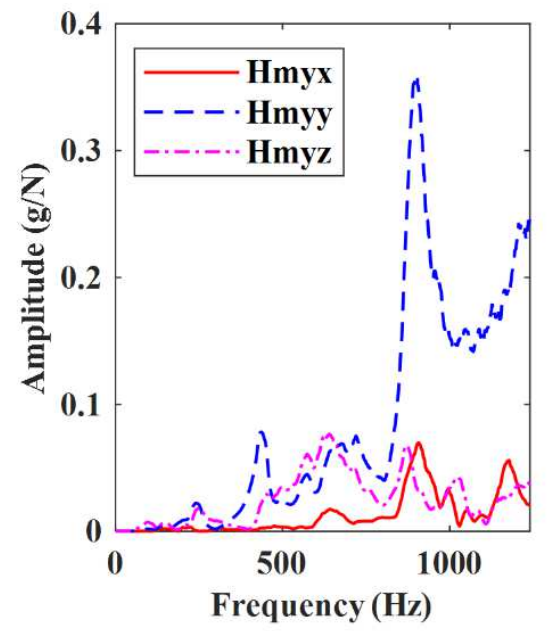

(b) Impact tool from Y-direction

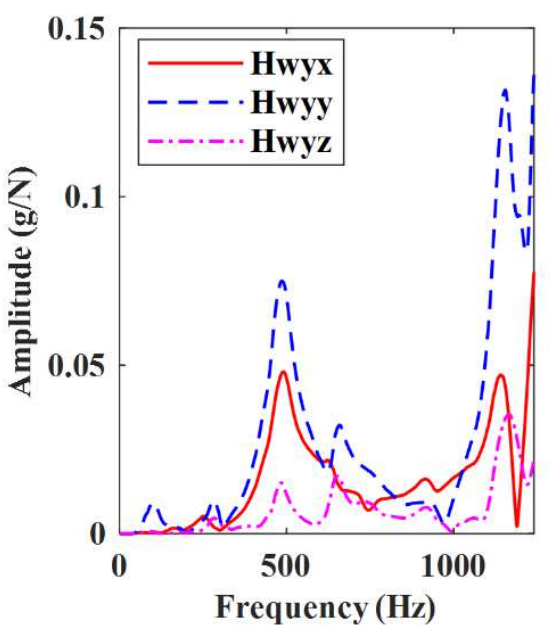

(e) Impact workpiece from Y-direction

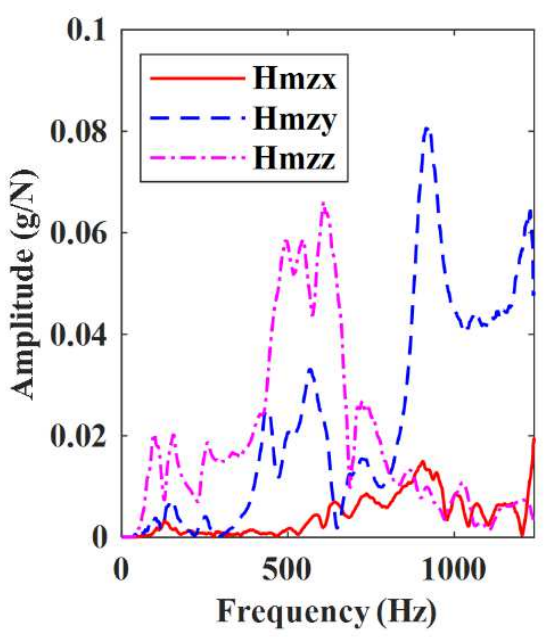

(c) Impact tool from Z-direction

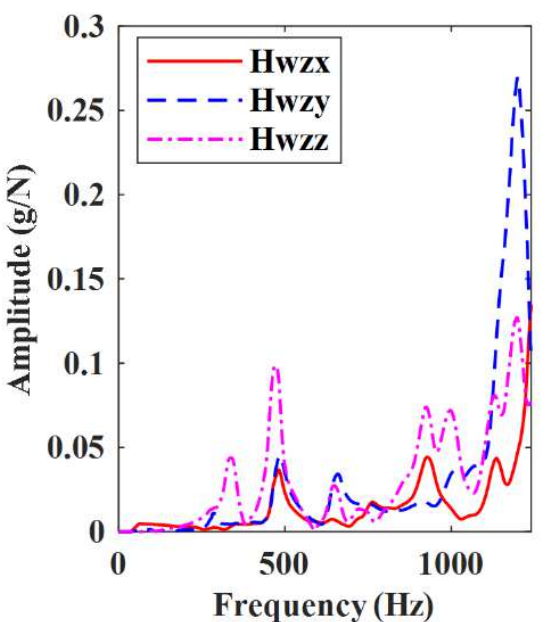

(f) Impact workpiece from Z-direction

Fig. 5 The FRFs of the spindle and the workpiece in the impact tests

\subsection{Dynamic Milling Force and Vibration}

\subsubsection{Force and Vibration Signals in the Milling Process}

Take the ninth experiment as an example, the original force and vibration signals produced during the milling process are demonstrated in Fig. 6, which show the components of the cutting forces and vibrations in different directions. The forces in three directions ranges from $-30 \mathrm{~N}$ to $30 \mathrm{~N}$ due to the alternative cutter tooth. The vibrations of spindle are larger than those of the workpiece, which indicates the workpiece receives smaller impacts under good clamping stiffness.

Based on the aforementioned analysis, the original signals contain not only the forces and vibrations produced by the milling process, but also affected by the spindle and the machine tool. Therefore, these milling signals require preprocessing to distinguish the forces and vibrations generated by the different causes. 


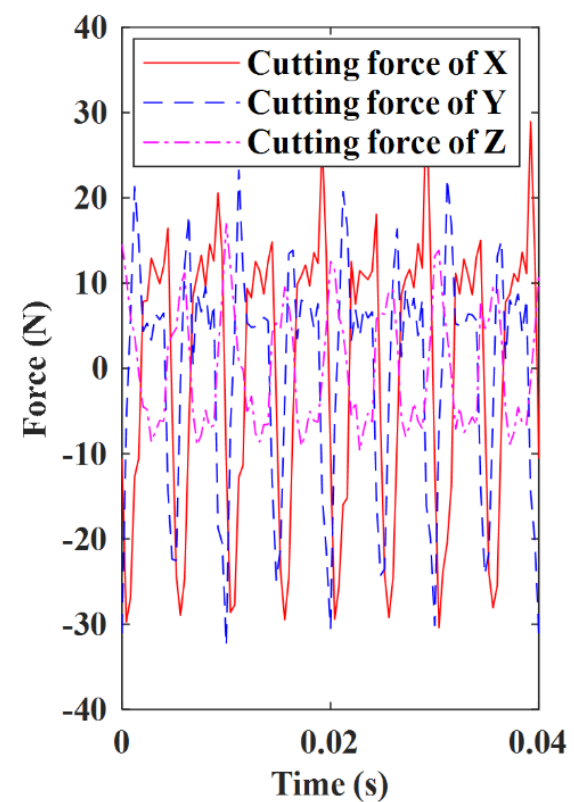

(a) Cutting forces

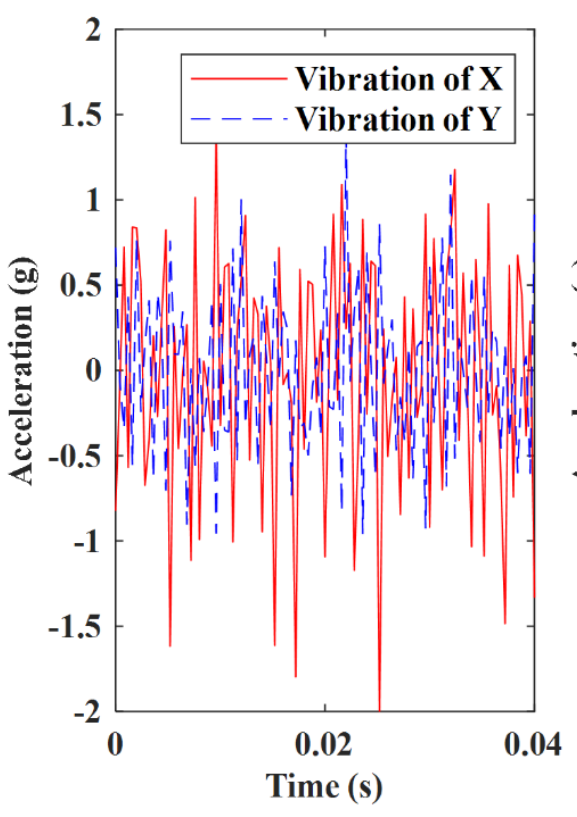

(b) Vibrations of spindle

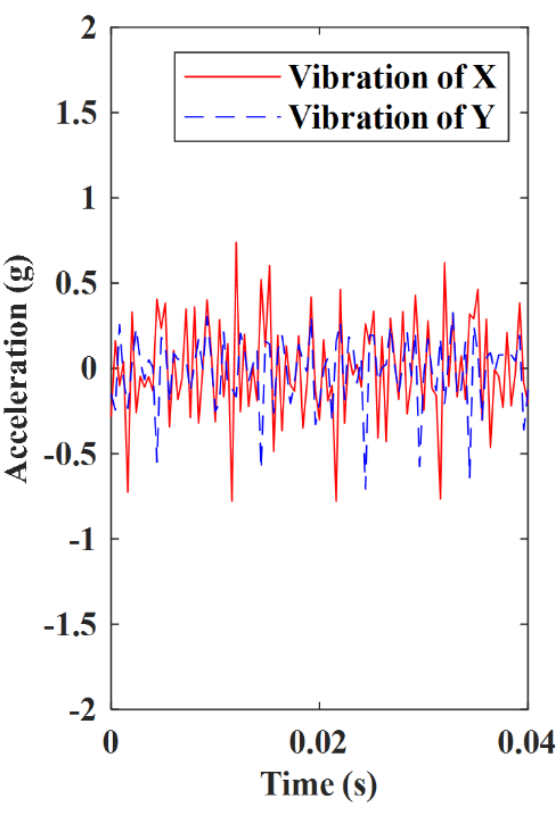

(c) Vibrations of workpiece

Fig. 6 The forces and vibrations produced in the milling process in different directions

\subsubsection{Preprocessing of the Milling Force Signal}

The frequency spectrums of the milling force signals are shown in Fig. 7, dynamic forces generated during the milling process consist of two parts: one is the periodic component produced by the periodic rotary motion of the spindle, which has extremely high energy and will cause the periodic interaction vibration of machine tool; the other is the random fluctuating component of cutting force. Therefore, in order to extract the periodic components and get accurate interaction effect analysis [27], wavelet packet transform is applied to preprocess the force signals.

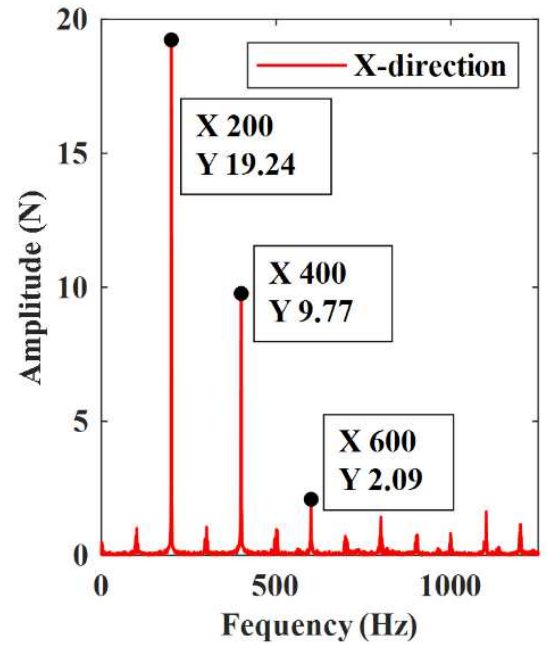

(a) X-direction

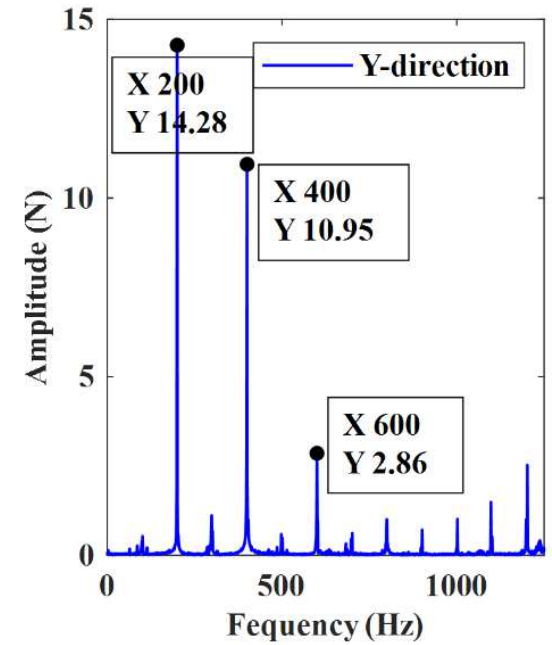

(b) Y-direction

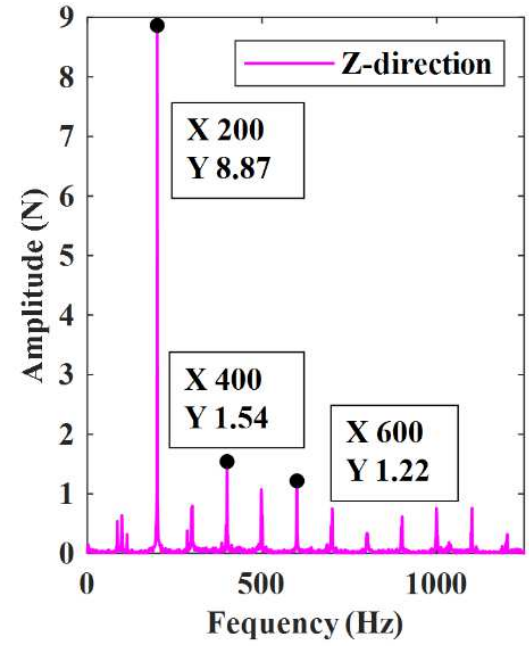

(c) Z-direction

Fig. 7 The spectrums of the actual milling force signal in different directions 
The milling force signal is decomposed into four layers using the dmey wavelet. The optimal wavelet packet decomposition tree is shown in Fig. 8. The decomposition result of the wavelet packet is called the wavelet coefficient and designated as $S_{4}^{0}, S_{4}^{1}, S_{4}^{1}, \cdots$. The wavelet coefficients of each node in the fourth layer are reconstructed using the wavelet packet reconstruction algorithm, so that the original force signal is represented as follows:

$$
S=S_{4}^{0}+S_{4}^{1}+, \cdots,+S_{4}^{15}
$$

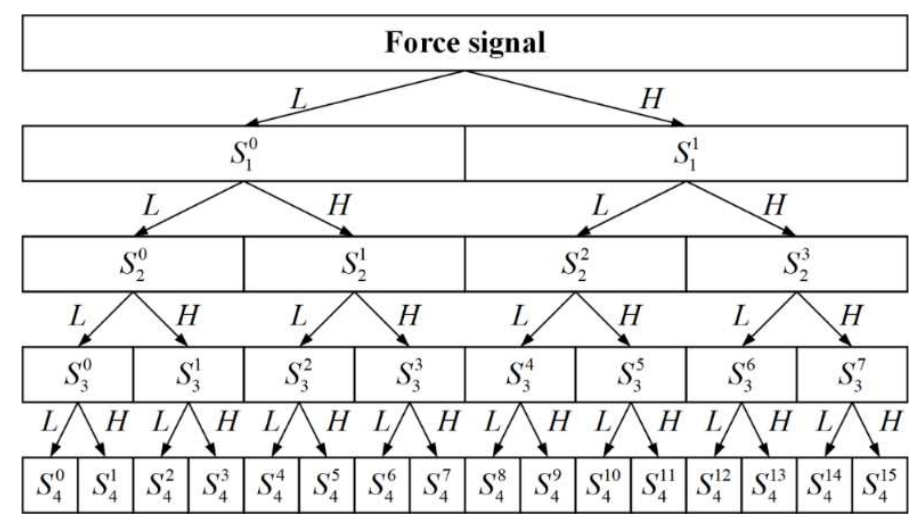

Fig. 8 Four-level decomposition structure of wavelet packet

The entropy of each band is acquired as $\mathrm{E}(4,0), \mathrm{E}(4,1), \cdots, \mathrm{E}(4,15)$, and these entropies are normalized using Eq. (31). The energy distribution of each frequency band of the milling force signal in the $\mathrm{X}, \mathrm{Y}$, and $\mathrm{Z}$ directions are shown in Fig. 9.

$$
H_{(4, j)}=\frac{E_{(4, j)}}{\sqrt{\sum_{j=0}^{15} E_{(4, j)}^{2}}}
$$

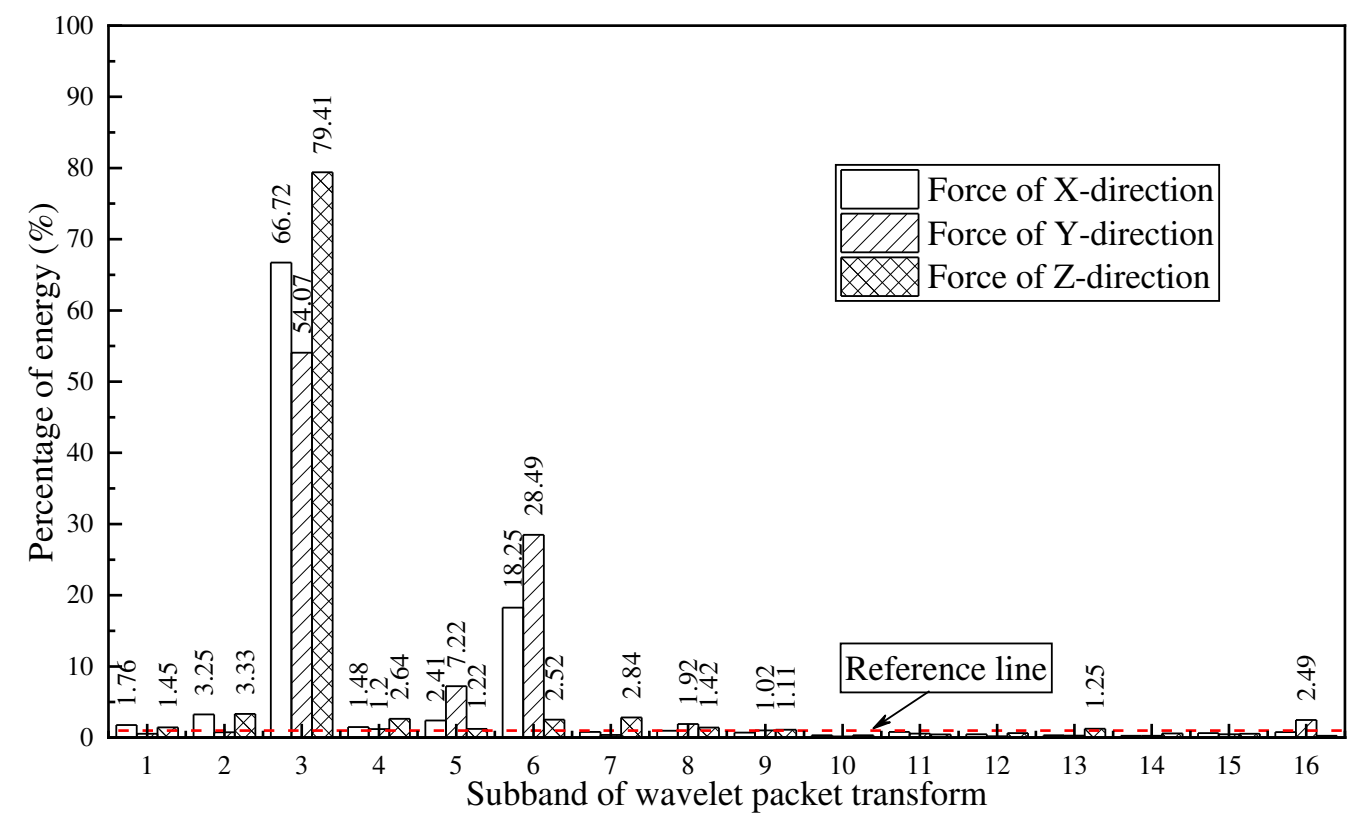

Fig. 9 The energy distribution in each band of the wavelet packet reconstructed signal 
In order to analyze the differences in working state in different frequency bands and identify the corresponding relationship between energy distribution and working state, the reconstructed signals of all nodes in the fourth layer are analyzed by fast Fourier transform in the frequency domain. Taking the milling force signal in the Y direction (the feed direction) as an example, spectrums of each node in the fourth layer are shown in Fig. 10.

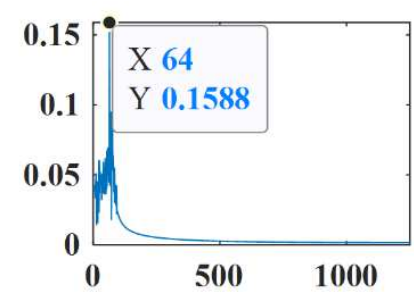

(a) Subband $(4,0)$

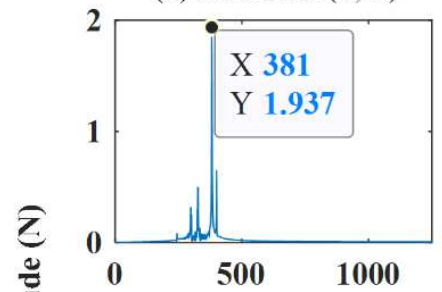

(e) Subband $(4,4)$

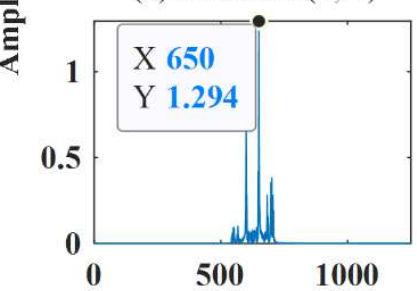

(i) Subband $(4,8)$

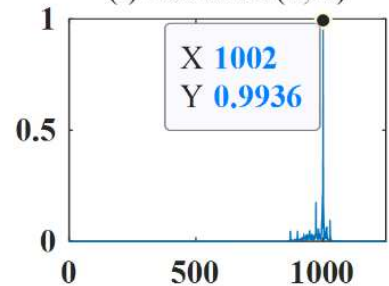

(m) Subband $(4,12)$

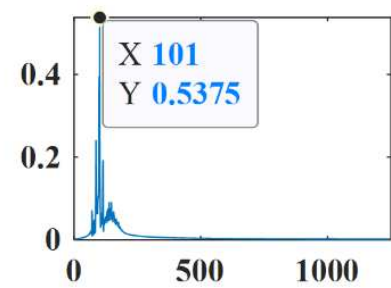

(b) Subband $(4,1)$

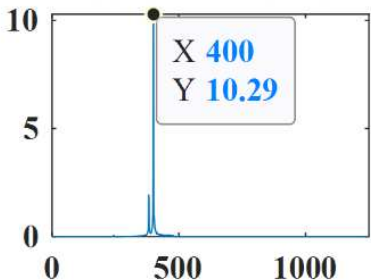

(f) Subband $(4,5)$

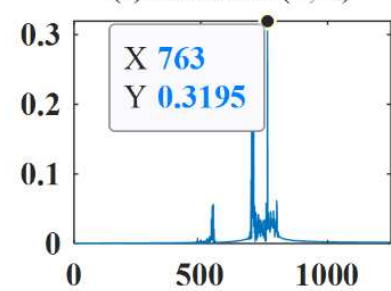

(j) Subband $(4,9)$

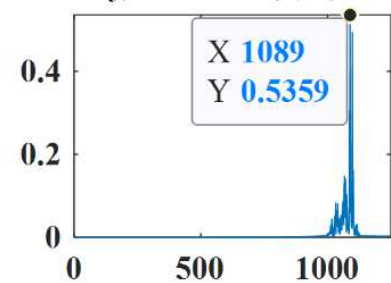

(n) Subband $(4,13)$

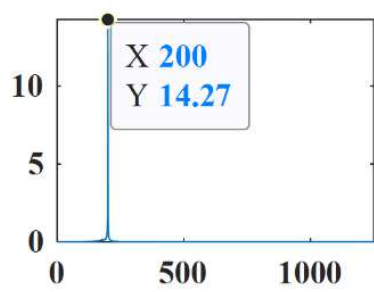

(c) Subband $(4,2)$

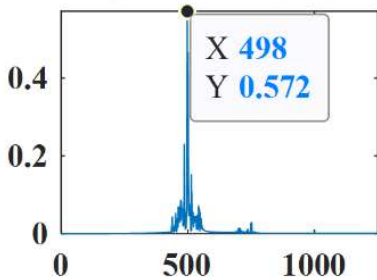

(g) Subband $(4,6)$

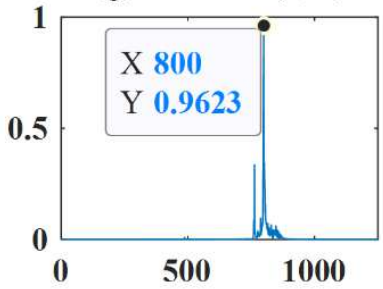

(k) Subband $(4,10)$

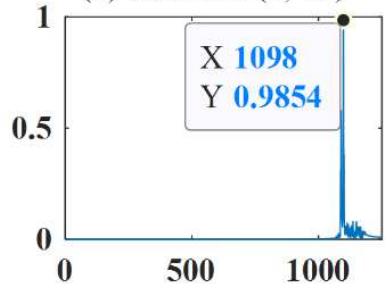

(o) Subband $(4,14)$

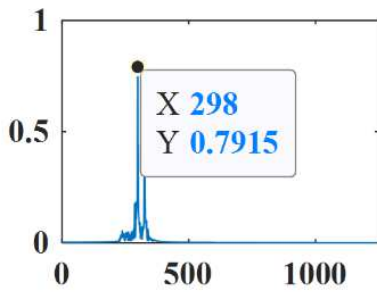

(d) Subband (4, 3)

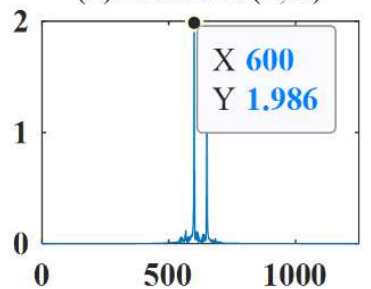

(h) Subband $(4,7)$

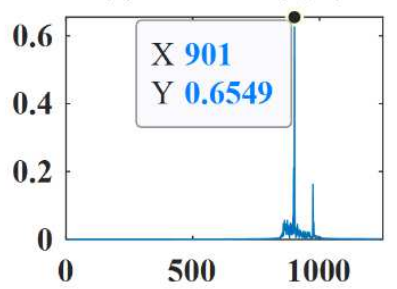

(1) Subband $(4,11)$

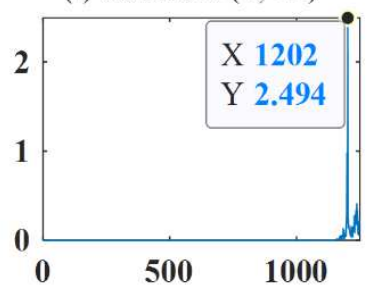

(p) Subband $(4,15)$

Frequency $(\mathrm{Hz})$

Fig. 10 The spectrums of the force signal in the $\mathrm{Y}$ direction applying wavelet packet decomposition

With the help of fast Fourier transformation, frequency bands with larger energy distribution can be selected to construct the milling force equation. According to the principle of the wavelet packet energy spectrum, several frequency bands of the force in Y direction with energy ratios greater than $1 \%$ (the Reference line in Fig. 9) are selected, while those with energy ratios close to 0 are abandoned. The sum of the cosine signals of these selected frequency bands is applied to express the milling force 
equation $F(\tau)$, and the required main frequency, amplitude, and phase information of the milling force signal in the $\mathrm{Y}$ direction are shown in Table 2.

Table 2 The wavelet packet decomposition information of the milling force signal in the $\mathrm{Y}$ direction

\begin{tabular}{cccccccc}
\hline Nodes & $(4,2)$ & $(4,3)$ & $(4,4)$ & $(4,5)$ & $(4,7)$ & $(4,8)$ & $(4,15)$ \\
\hline Frequency band (Hz) & $156-233$ & $234-311$ & $312-389$ & $390-467$ & $546-623$ & $624-701$ & $1173-1250$ \\
Energy distribution (\%) & 54.07 & 1.20 & 7.22 & 28.49 & 1.92 & 1.02 & 2.49 \\
Main frequency (Hz) & 200 & 298 & 381 & 400 & 600 & 650 & 1202 \\
Amplitude (N) & 14.27 & 0.79 & 1.94 & 10.29 & 1.99 & 1.29 & 2.49 \\
Phase (rad) & -3.05 & 3.08 & 1.07 & 2.80 & 2.25 & 0.91 & 2.48 \\
\hline
\end{tabular}

Therefore, the milling force equation calculated in the $\mathrm{Y}$ direction according to the original force signal is as follows:

$$
\begin{aligned}
& F_{y}=14.27 \cos (2 p i * 200 t-3.05)+0.79 \cos (2 p i * 298 t+3.08) \\
& +1.94 \cos (2 p i * 381 t+1.07) \\
& +10.29 \cos (2 p i * 400 t+2.80)+1.99 \cos (2 p i * 600 t+2.25) \\
& \quad+1.29 \cos (2 p i * 650 t+0.91) \\
& +2.49 \cos (2 p i * 1202 t+2.48)
\end{aligned}
$$

Similarly, the milling force equation in the $\mathrm{X}$ direction can be obtained as follows by using the same processing method:

$$
\begin{aligned}
& F_{x}=0.17 \cos (2 p i * 79 t-1.80)+0.97 \cos (2 p i * 101 t+1.89) \\
&+19.16 \cos (2 p i * 200 t+1.89) \\
&+ 0.68 \cos (2 p i * 301 t+0.84)+1.68 \cos (2 p i * 381 t+3.00) \\
& \quad+9.21 \cos (2 p i * 400 t+1.01) \\
&+ 1.45 \cos (2 p i * 600 t+1.06)+1.34 \cos (2 p i * 800 t+1.79)
\end{aligned}
$$

Then the milling force equation in the $\mathrm{Z}$ direction can be obtained as follows:

$$
\begin{aligned}
F_{z}= & 0.18 \cos (2 p i * 70 t-0.72)+0.63 \cos (2 p i * 99 t-0.54)+8.84 \cos (2 p i * 200 t-0.76) \\
+ & 0.58 \cos (2 p i * 301 t-3.12)+0.35 \cos (2 p i * 326 t+0.94) \\
& +1.44 \cos (2 p i * 400 t-1.68) \\
+ & 1.07 \cos (2 p i * 498 t+1.68)+0.85 \cos (2 p i * 600 t+0.76) \\
& +0.56 \cos (2 p i * 650 t+0.36) \\
+ & 0.74 \cos (2 p i * 999 t-0.81)
\end{aligned}
$$


The force equations can be applied in predicting the milling force signal. The predicted signal not only eliminates noise while retaining feature information, but also avoids the influence of aperiodic truncation on the signal. The predicted force signals based on the Eqs. (32) - (34) are shown in Fig. 11 which contain characteristic components in milling and match well with the dynamic force model.

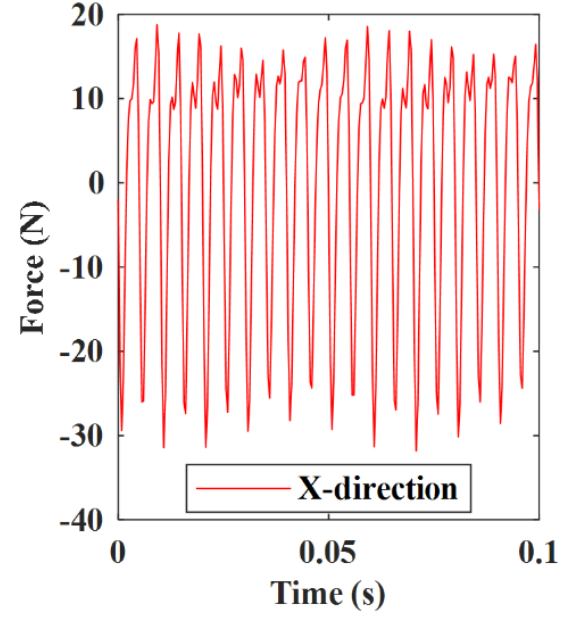

(a) Predicted force of X-direction

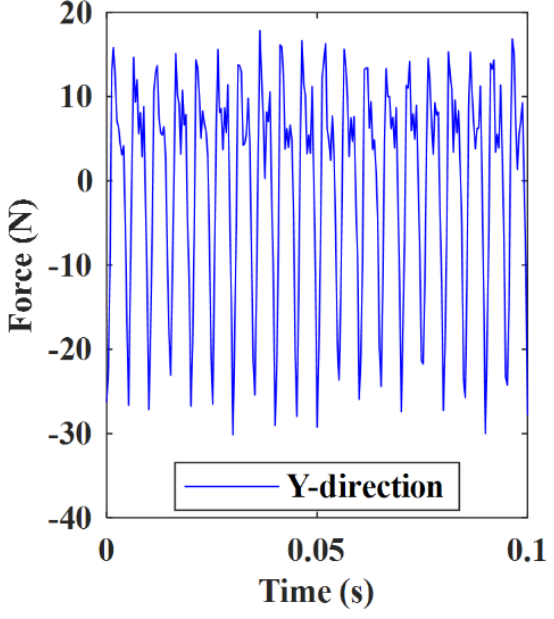

(b) Predicted force of $\mathrm{Y}$-direction

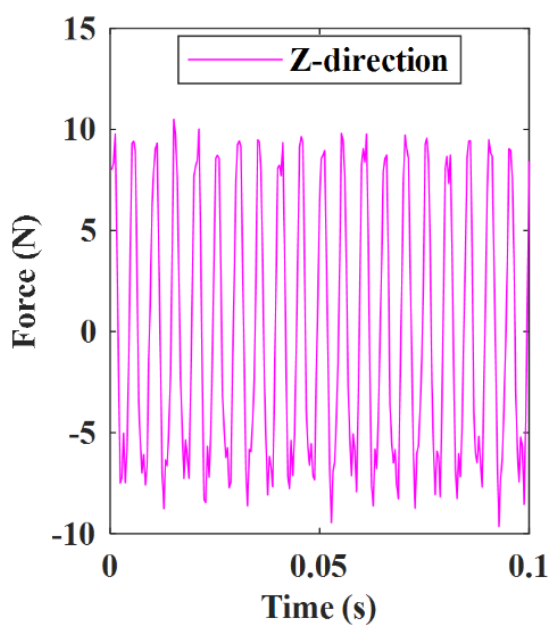

(c) Predicted force of Z-direction

Fig. 11 The predicted milling force signal in different directions

\subsubsection{Preprocessing of the Spindle Free-run Signal}

As shown in Eq. (28) in the modelling, the spindle free-run signal is superposed on the forced vibration signal. The measured spindle free-run vibration signal and its spectrum are shown in Fig. 12.

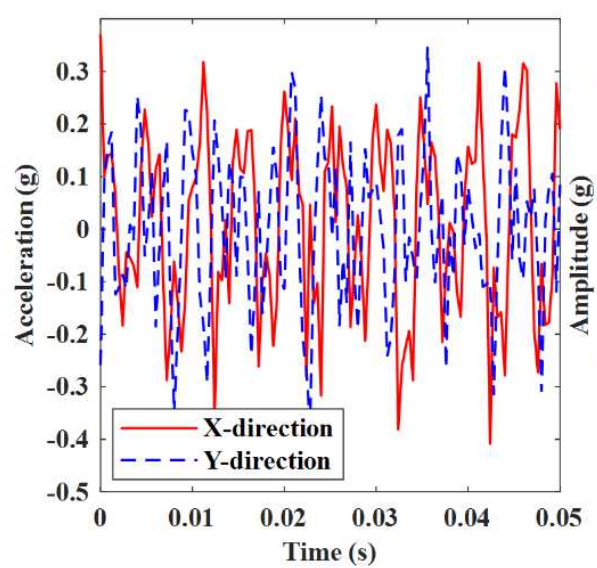

(a) Spindle free-run vibration signal

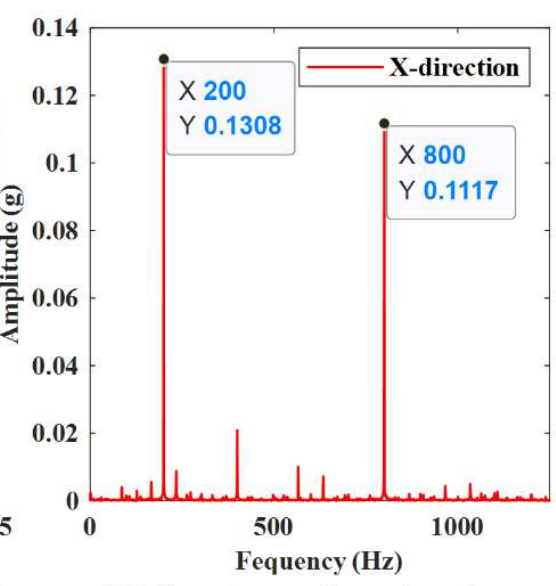

(b) Spectrum of acceleration in X-direction

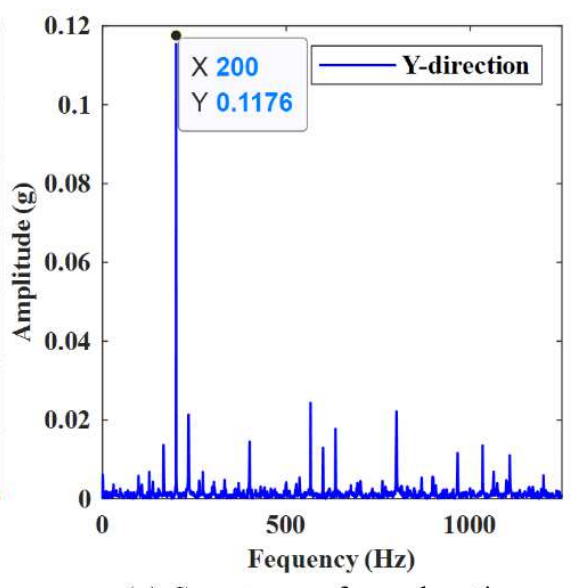

(c) Spectrum of acceleration in Y-direction

Fig. 12 The spindle free-run vibration signal and its frequency spectrum in the $X$ and $Y$ directions

The previous preprocessing method is also applied to extract the characteristic frequency information of the measured spindle free-run signal. After being decomposed into four layers by dmey 
wavelet, the energy distribution of each frequency band of the spindle free-run signal in the $\mathrm{X}$ and $\mathrm{Y}$ directions are shown in Fig. 13.

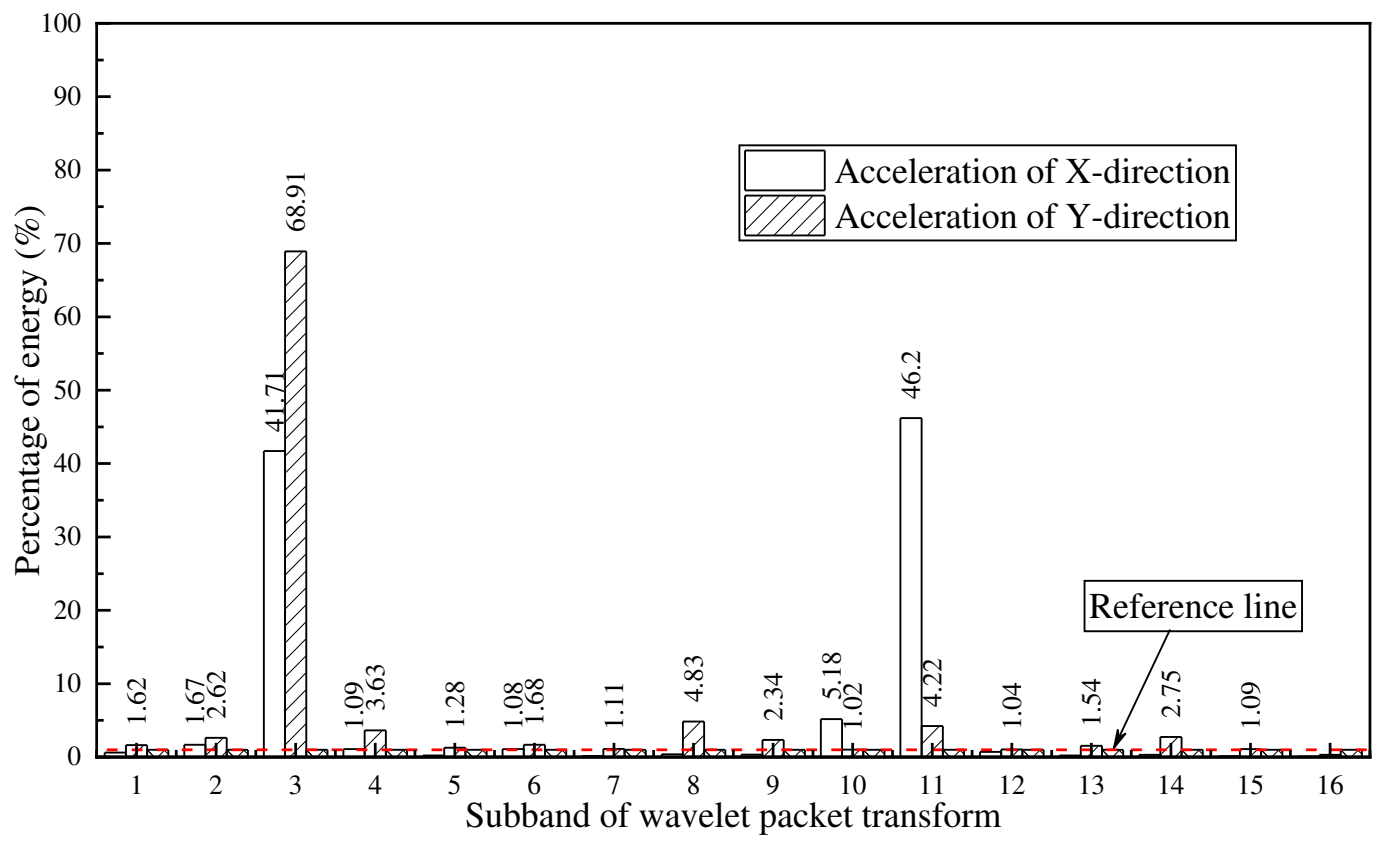

Fig. 13 The energy distribution in each band of the wavelet packet reconstructed signal

Taking the spindle free-run vibration signal in the $\mathrm{X}$ direction as an example, spectrums of each node in the fourth layer are shown in Fig. 14.
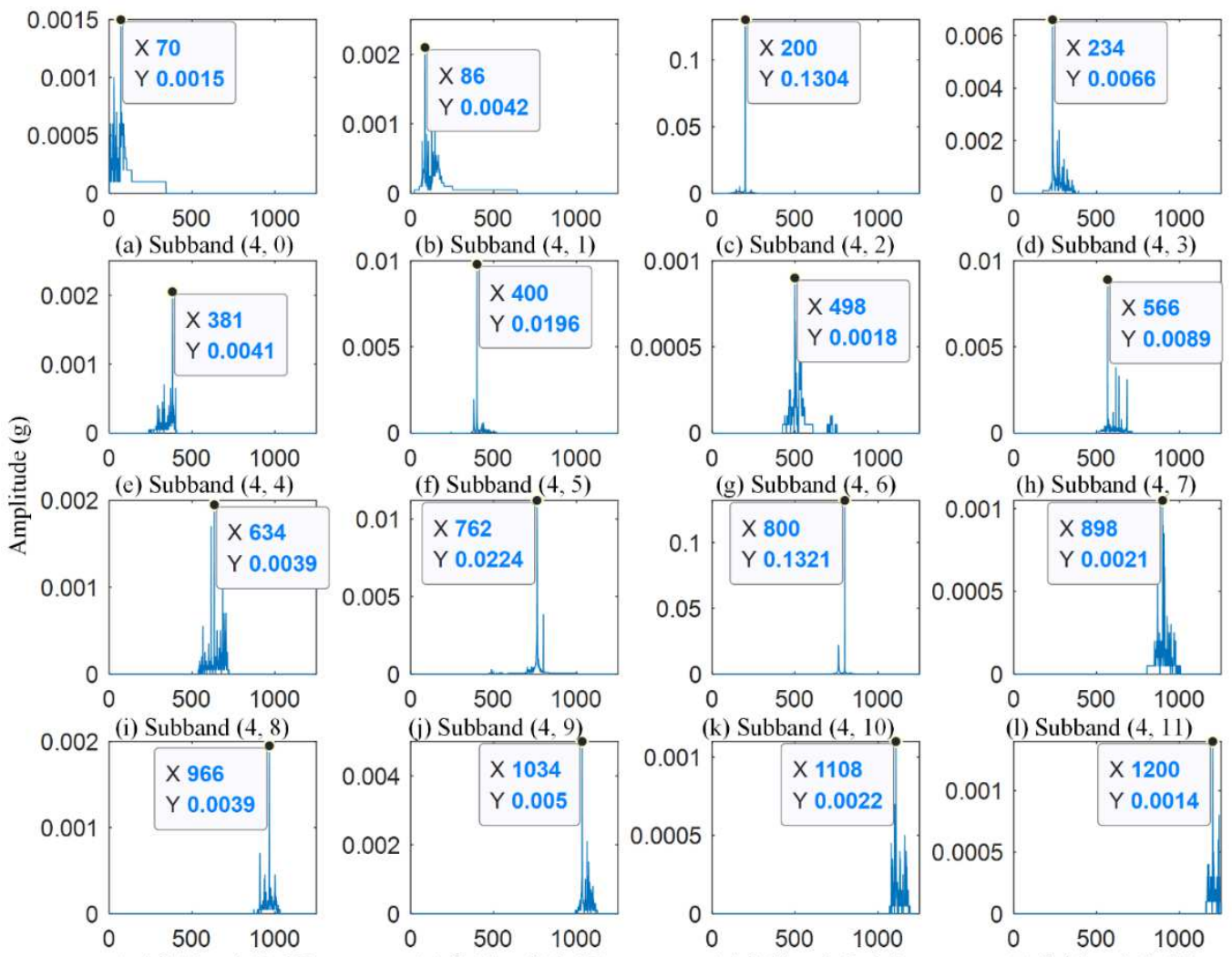

(m) Subband $(4,12)$

(n) Subband $(4,13)$

(o) Subband $(4,14)$

(p) Subband $(4,15)$ 
Fig. 14 The spectrums of spindle free-run vibration signal in the $X$ direction applying wavelet packet decomposition

According to the principle of wavelet packet energy detection, main frequency bands (energy ratio greater than $1 \%$, evaluated by the Reference line in Fig. 13) are selected to construct the free-run vibration equation $a(\tau)$ of the spindle. The required main frequency, amplitude, and phase information of the spindle free-run vibration signal in the $\mathrm{X}$ direction are shown in Table 3.

Table 3 The wavelet packet decomposition of the spindle free-run vibration signal in the $\mathrm{X}$ direction

\begin{tabular}{ccccccc}
\hline Selected nodes & $(4,1)$ & $(4,2)$ & $(4,3)$ & $(4,5)$ & $(4,9)$ & $(4,10)$ \\
\hline Frequency band (Hz) & $78-155$ & $156-233$ & $234-311$ & $390-467$ & $702-779$ & $780-857$ \\
Energy distribution (\%) & 1.67 & 41.71 & 1.09 & 1.08 & 5.18 & 46.20 \\
Main frequency (Hz) & 86 & 200 & 234 & 400 & 762 & 800 \\
Amplitude (g) & 0.004 & 0.130 & 0.007 & 0.020 & 0.022 & 0.132 \\
Phase (rad) & 1.46 & -1.90 & 0.56 & -1.84 & -0.08 & 0.88 \\
\hline
\end{tabular}

The spindle free-run vibration equations can be expressed as the sum of multiple cosine signals:

$$
\begin{gathered}
a_{x}=0.004 \cos (2 \mathrm{pi} * 86 \mathrm{t}+1.46)+0.130 \cos (2 \mathrm{pi} * 200 \mathrm{t}-1.90) \\
+0.007 \cos (2 \mathrm{pi} * 234 \mathrm{t}+0.56) \\
+0.020 \cos (2 \mathrm{pi} * 400 \mathrm{t}-1.84)+0.022 \cos (2 \mathrm{pi} * 762 \mathrm{t}-0.08) \\
+0.132 \cos (2 \mathrm{pi} * 800 \mathrm{t}+0.88) \\
a_{y}=0.006 \cos (2 \mathrm{pi} * 127 \mathrm{t}+2.68) \\
+0.117 \cos (2 \mathrm{pi} * 200 \mathrm{t}+0.92)+0.016 \cos (2 \mathrm{pi} * 234 \mathrm{t}+0.56) \\
+0.013 \cos (2 \mathrm{pi} * 400 \mathrm{t}+0.70)+0.020 \cos (2 \mathrm{pi} * 566 \mathrm{t}+1.10) \\
\quad+0.009 \cos (2 \mathrm{pi} * 634 \mathrm{t}+1.20) \\
+0.019 \cos (2 \mathrm{pi} * 800 \mathrm{t}-2.35)+0.013 \cos (2 \mathrm{pi} * 1034 \mathrm{t}-1.86)
\end{gathered}
$$

For the same time series $t$, the preprocessed milling force signal and the preprocessed spindle free-run vibration signal can be ensured to be synchronized in the time domain. The predicted spindle free-run vibration signals based on the Eqs. (35) - (36) are shown in Fig. 15. 


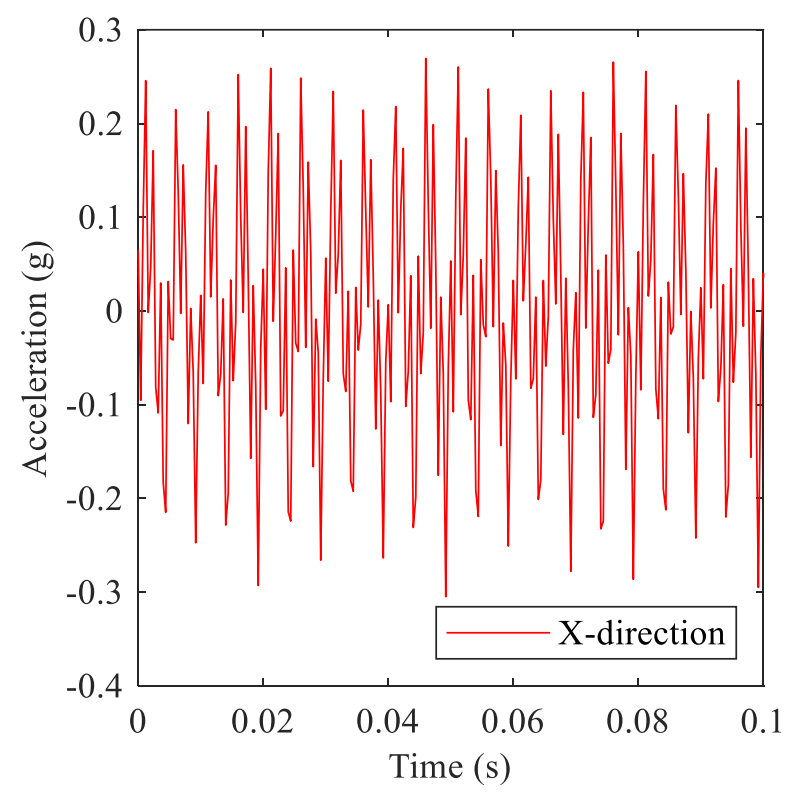

(a) Predicted spindle free-run vibration of X-direction

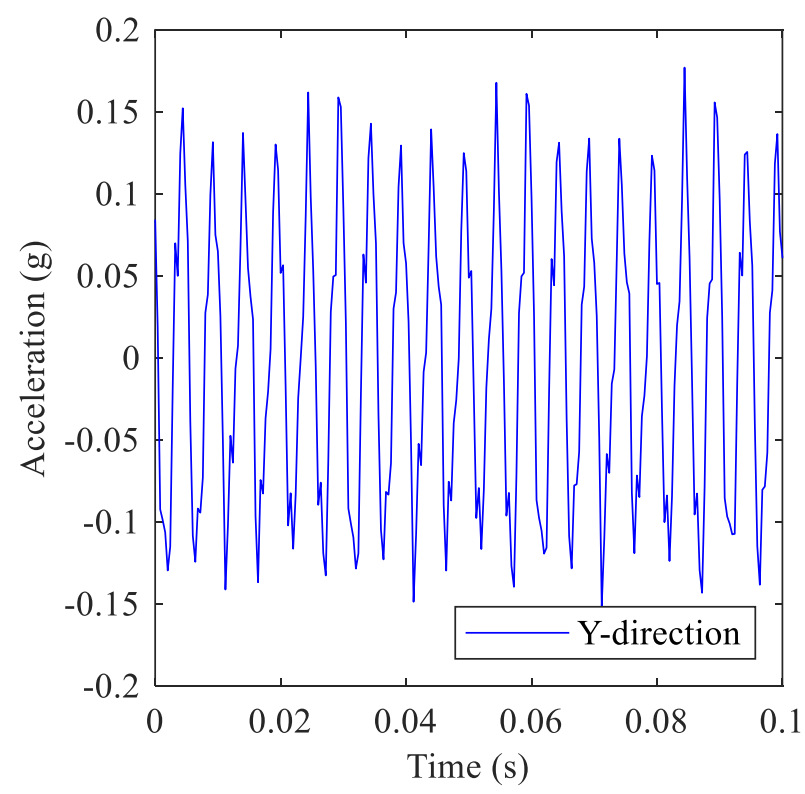

(b) Predicted spindle free-run vibration of Y-direction

Fig. 15 The predicted spindle free-run vibration signals in different directions

\subsection{Comparison of Interaction Analysis Result}

The manufacturing process and machine interaction shows that the process cutting force would result in machine vibration. The interaction effect based on forced vibration theory in equations is investigates applying the frequency-domain dynamic force and frequency response function. In interaction analysis, the predicted vibration is calculated in the proposition of process interaction by applying Eqs. (28) - (29). The time-domain signals of the predicted vibration and the actual measured vibration are shown in Fig. 16. It can be seen that the predicated results obtained in interaction effect approach matches with the vibration signal direct tested, whether they come from the measurement point of the spindle or the workpiece. 

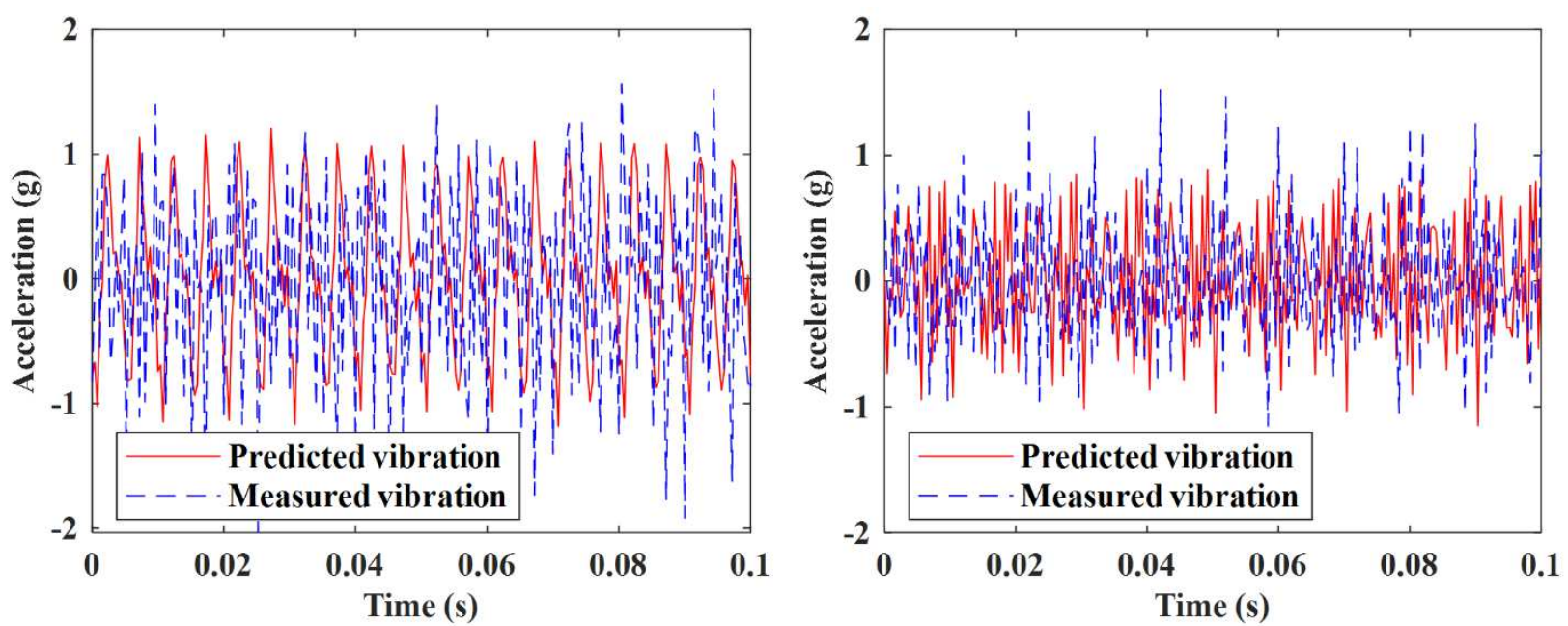

(a) Comparison of spindle vibrations in $\mathrm{X}$ direction

(b) Comparison of spindle vibrations in $\mathrm{Y}$ direction

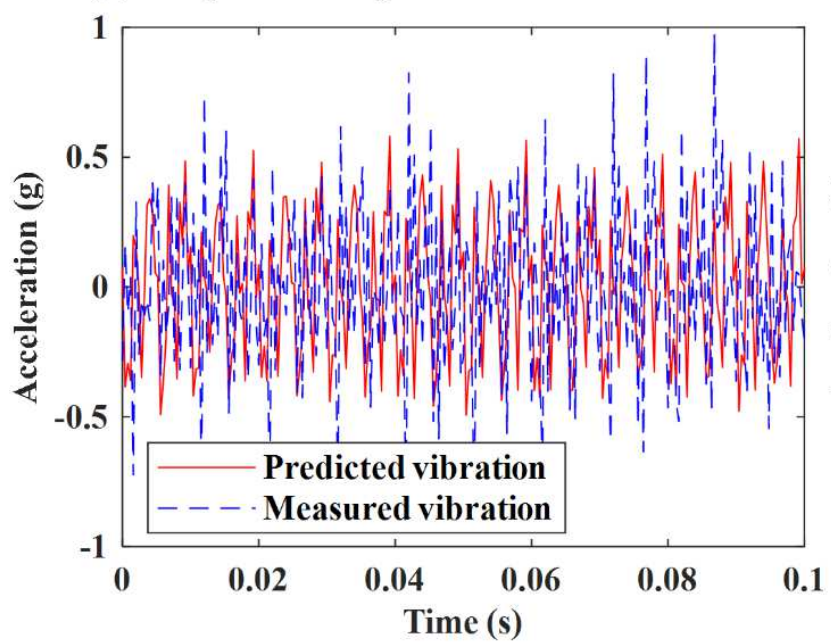

(c) Comparison of workpiece vibrations in $\mathrm{X}$ direction

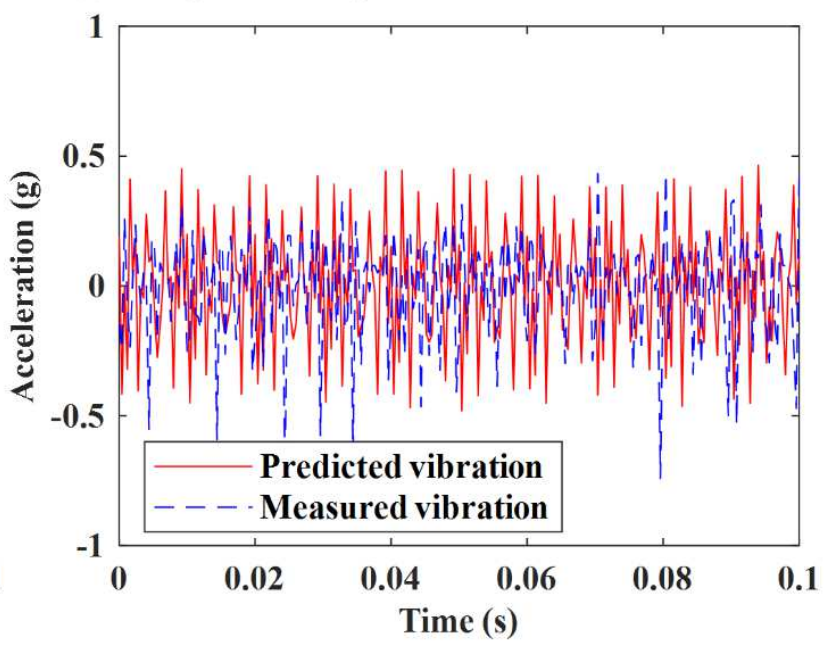

(d) Comparison of workpiece vibrations in Y direction

Fig. 16 Comparison between the predicted vibration and the measured vibration (Exp. no. 9)

In order to compare the amplitude of the calculated vibration and the actual measured vibration in the frequency domain, the spectrums of two vibration signals are shown in Fig. 17. It shows that the main frequencies of the vibration signal spectrograms in the $\mathrm{X}$ and $\mathrm{Y}$ directions of the spindle are close at $200 \mathrm{~Hz}, 400 \mathrm{~Hz}$, and $600 \mathrm{~Hz} .200 \mathrm{~Hz}$ is the rotational frequency of the spindle, $400 \mathrm{~Hz}$ is the double frequency of the rotational frequency, and $600 \mathrm{~Hz}$ (the tooth-passing frequency) is the three-times frequency of the rotational frequency. Therefore, the amplitudes of the characteristic frequency at the low frequency match well. However, at the high frequency, there is some differences due to the extraction method of the signal and some other unpredictable effects. 


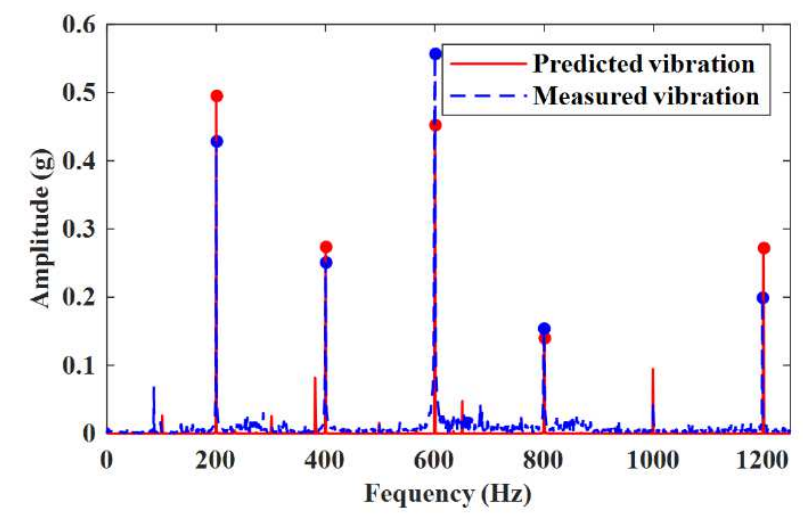

(a) Spectrum of spindle vibration signal in X-direction

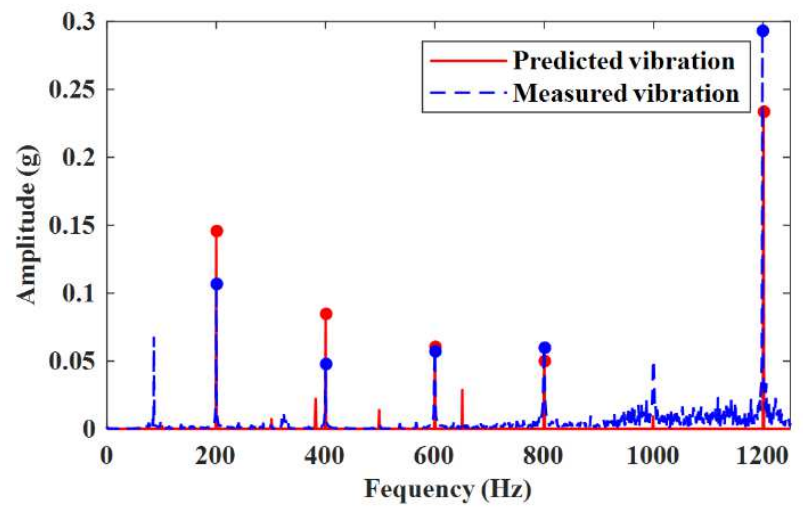

(c) Spectrum of workpiece vibration signal in X-direction

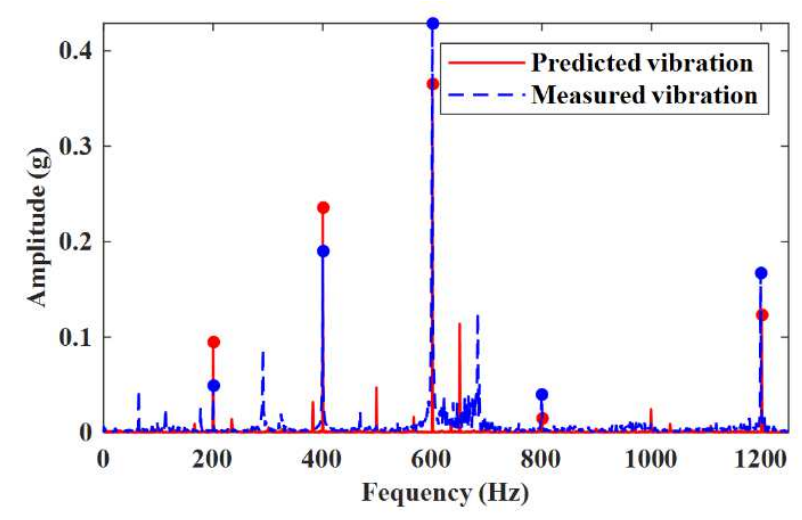

(b) Spectrum of spindle vibration signal in Y-direction

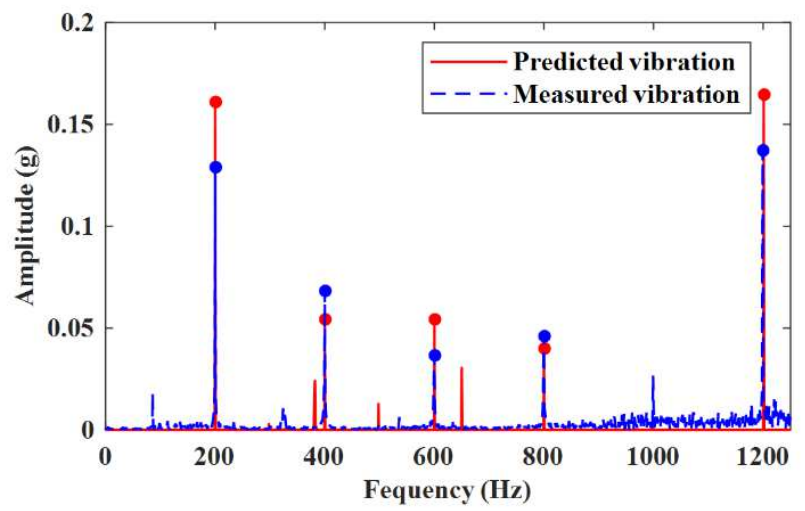

(d) Spectrum of workpiece vibration signal in Y-direction

Fig. 17 Spectrum of the predicted vibration and the measured vibration (Exp. no. 9)

In order to determine the magnitude error of the predicted vibration, the root mean square (RMS) of the vibration signal is calculated using Eq. (37) in which measured vibration signal and the calculated vibration are $\mu_{a}$ and $\mu_{\hat{a}}$, respectively, and the relative error of the RMS between the two can be expressed as:

$$
\begin{aligned}
& \text { Vibration }_{r m s}=\sqrt{\frac{1}{N} \sum_{i=1}^{N} a(i)^{2}} \\
& \varepsilon_{r m s}=\frac{\left|\mu_{\widehat{a}}-\mu_{a}\right|}{\mu_{a}} \times 100 \%
\end{aligned}
$$

Table 4 lists the RMS error of the predicted vibrations of the spindle and the workpiece under all precision milling parameter combinations. After statistical calculation, the overall percentage of the errors of vibrations from the spindle and the workpiece in $\mathrm{X}$ and $\mathrm{Y}$ directions are around 20.8\%,21.8\%, $17.4 \%$ and $17.6 \%$ respectively. The prediction error of the spindle vibration is larger than that of the workpiece vibration, which can be attribute to the complex structure of the spindle. The vibration of the spindle consists of the vibrations from various components, such as bearings and sleeves, and is prone to producing vibrations in different dominant frequencies. On the other hand, the vibration of 
the workpiece is mainly composed by the self-excited vibrations from workpiece and the tool. The spindle speed and the number of cutter tooth influence the dominant frequencies significantly, which is easier to be identified through spectral analysis and can be predicted better.

Table 4 The relative RMS error of the vibrations

\begin{tabular}{|c|c|c|c|c|c|c|c|}
\hline \multirow[t]{2}{*}{ Exp. no. } & \multicolumn{3}{|c|}{ Factors } & \multicolumn{2}{|c|}{$\begin{array}{c}\text { RMS error of } \\
\text { spindle vibration (\%) }\end{array}$} & \multicolumn{2}{|c|}{$\begin{array}{c}\text { RMS error of } \\
\text { workpiece vibration }(\%)\end{array}$} \\
\hline & $n(\mathrm{r} / \mathrm{min})$ & $v_{f}(\mathrm{~m} / \mathrm{min})$ & $\alpha_{p}(\mathrm{~mm})$ & $\mathrm{X}$-direction & Y-direction & $\mathrm{X}$-direction & Y-direction \\
\hline 1 & 8000 & 0.4 & 0.3 & 25.1 & 27.3 & 22.7 & 18.3 \\
\hline 2 & 8000 & 0.6 & 0.4 & 22.4 & 21.1 & 19.5 & 17.7 \\
\hline 3 & 8000 & 0.8 & 0.5 & 19.2 & 25.2 & 13.8 & 18.2 \\
\hline 4 & 10000 & 0.4 & 0.4 & 24.7 & 19.8 & 15.2 & 22.3 \\
\hline 5 & 10000 & 0.6 & 0.5 & 23.1 & 23.3 & 23.4 & 19.6 \\
\hline 6 & 10000 & 0.8 & 0.3 & 17.5 & 23.6 & 11.6 & 13.7 \\
\hline 7 & 12000 & 0.4 & 0.5 & 17.2 & 19.2 & 15.2 & 13.4 \\
\hline 8 & 12000 & 0.6 & 0.3 & 21.4 & 18.5 & 20.3 & 17.1 \\
\hline 9 & 12000 & 0.8 & 0.4 & 16.2 & 18.1 & 14.7 & 18.0 \\
\hline
\end{tabular}

\section{CONCLUSIONS}

This paper investigated the interaction effect between the dynamic force and the vibration response in the precision milling of 7075-T651 based on forced-vibration transformation approach. By both theoretical modelling and experimental verification, the following conclusions can be drawn from the above investigation:

- The interaction vibration is excited by both the machine tool load and machining process dynamic load, the dynamic excitation loads and the vibration response can be superimposed under the linear system assumption. The spindle-tool structural dynamic characteristics is the interaction link between the dynamic force load and the vibration response, even in non-chatter condition, it mainly determines the accuracy level in precision milling applications.

- The forces and vibrations can be expressed by the linear combinations of various frequency components. These frequency components are selected by the entropies in the wavelet packets due to the large quantities of the energies being found in the dominant frequencies. The proposed forces and vibrations prediction method shows high consistencies with the measured values.

- The overall percentage of the errors of predicted vibrations from the spindle and the workpiece in $\mathrm{X}$ and $\mathrm{Y}$ directions are controlled at around $20.8 \%, 21.8 \%, 17.4 \%$ and $17.6 \%$ respectively. The 
lower errors of workpiece vibrations indicates that the self-excited vibrations generated by the workpiece and the tool can be identified and predicted better than spindle vibrations.

\section{Funding}

Natural Science Foundation of China (No. 51905347), Recipient: Miaoxian Guo.

\section{Conflicts of interest/Competing interests}

The authors declare that they have no conflict of interest or competing interests.

\section{Availability of data and materials}

The data and materials that support the findings of this study are available from the corresponding author upon reasonable request.

\section{Code availability}

Not applicable.

\section{Ethical Approval}

Compliance with ethical standards.

\section{Consent to Participate and Publish}

The authors consent to participate and publish.

\section{Authors Contributions}

Weicheng Guo: Data collection, validation, writing original manuscript.

Miaoxian Guo: Conceptualization, methodology.

Ye Yi: Graphic plotting.

Chongjun $\mathrm{Wu}$ : Manuscript revision.

Jiang Xiaohui: Supervision. 


\section{REFERENCES}

[1] C. Brecher, M. Esser, S. Witt. Interaction of manufacturing process and machine tool. CIRP Annals Manufacturing Technology, 2009, 58(2): 588-607.

[2] E. Uhlmann, F. Mahr, Y. Shi, U. von Wagner. Process Machine Interactions in Micro Milling, in Lecture Notes in Production Engineering. 2013: 265-284.

[3] S.J. Zhang, S. To, G.Q. Zhang, Z.W. Zhu. A review of machine-tool vibration and its influence upon surface generation in ultra-precision machining. International Journal of Machine Tools and Manufacture, 2015, 91: 34-42. [4] S. Filiz. Vibrations of micro-scale cutting-tools and ultra-high-speed-spindles--modeling and experimentation. 2009, Carnegie Mellon University.

[5] S.J. Zhang, S. To. The effects of spindle vibration on surface generation in ultra-precision raster milling. International Journal of Machine Tools and Manufacture, 2013, 71: 52-56.

[6] S.J. Zhang, S. To. A theoretical and experimental study of surface generation under spindle vibration in ultraprecision raster milling. International Journal of Machine Tools and Manufacture, 2013, 75: 36-45.

[7] J. Ma, G. Hu, Z. Jia, N. Zhang, F. Wang. Effect of geometric feature and cutting direction on variation of force and vibration in high-speed milling of TC4 curved surface. The International Journal of Advanced Manufacturing Technology, 2018, 95(5-8): 2207-2218.

[8] B. Jiang, G. Cao, L. Zhang, M. Sun, S. Liu. Influence Characteristics of Tool Vibration and Wear on Machined Surface Topography in High-Speed Milling. Materials Science Forum, 2014, 800-801: 585-589.

[9] L. Zhu, C. Liu. Recent progress of chatter prediction, detection and suppression in milling, Mechanical Systems and Signal Processing, 2020, 143: 106840. https://doi.org/10.1016/j.ymssp.2020.106840.

[10] E. Graham, M. Mehrpouya, S. Park, Robust prediction of chatter stability in milling based on the analytical chatter stability, Journal Of Manufacturing Processes, 2013, 15(4): 508-517.

[11] C. Yue, H. Gao, X. Liu, S.Y. Liang, L. Wang. A review of chatter vibration research in milling. Chinese Journal of Aeronautics, 2019, 32(2): 215-242.

[12] C. Li, X. Li, Y. Wu, F. Zhang, H. Huang, Deformation mechanism and force modelling of the grinding of YAG single crystals. International Journal of Machine Tools \& Manufacture, 2019, 143, 23-37.

[13] Z. Ding, G. Sun, M. Guo, X. Jiang, B. Li, S.Y. Liang, Effect of phase transition on micro-grinding-induced 
residual stress, Journal of Materials Processing Technology, 2020, 281:116647.

https://doi:10.1016/j.jmatprotec.2020.116647

[14] C. Wu, J. Pang, B. Li, S. Y. Liang, High Speed Grinding of HIP-SiC Ceramics on Transformation of Microscopic Features. The International Journal of Advanced Manufacturing Technology, 2019, 102(5-8):1913-1921.

[15] D. Zhu, X. Feng, X. Xu, Z. Yang, W. Li, S. Yan, H. Ding, Robotic grinding of complex components: A step towards efficient and intelligent machining - challenges, solutions, and applications, Robotics and ComputerIntegrated Manufacturing, 2020, 65:101908. https://doi.org/10.1016/j.rcim.2019.101908

[16] P. Mativenga and K. Hon. An Experimental Study of Cutting Forces in High-Speed End Milling and Implications for Dynamic Force Modeling. ASME. Journal of Manufacturing Science and Engineering, 2005, 27(2): 251-261.

[17] Moradi H, Vossoughi G, Movahhedy MR (2013) Experimental dynamic modelling of peripheral milling with process damping, structural and cutting force nonlinearities. Journal of Sound and Vibration, 2013, 332:4709-4731.

[18] H. Cao, Y. Lei, Z. He, Chatter identification in end milling process using wavelet packets and Hilbert-Huang transform, International Journal of Machine Tools and Manufacture, 2013, 69: 11-19.

[19] X. Jiang, X. Kong, Z. Zhang, Z. Wu, Z. Ding, M. Guo. Modeling the effects of Undeformed Chip Volume (UCV) on residual stresses during the milling of curved thin-walled parts, International Journal of Mechanical Sciences, 2020, 167: 105162. https://doi.org/10.1016/j.ijmecsci.2019.105162.

[20] S. Wang, L. Geng, Y. Zhang, K. Liu, T.E. Ng, Cutting force prediction for five-axis ball-end milling considering cutter vibrations and run-out, International Journal Of Mechanical Sciences, 2015, 96-97:206-215.

[21] P. Albertelli, M. Goletti, M. Torta, M. Salehi, M. Monno. Model-based broadband estimation of cutting forces and tool vibration in milling through in-process indirect multiple-sensors measurements. International Journal of Advanced Manufacturing Technology, 2016, 82: 779-796.

[22] N. Grossi, L. Sallese, A. Scippa, G. Campatelli. Speed-varying cutting force coefficient identification in milling. Precision Engineering, 2015, 42: 321-334.

[23] M. Salehi, P. Albertelli, M. Goletti, F. Ripamonti, G. Tomasini, M. Monno. Indirect Model Based Estimation of Cutting Force and Tool Tip Vibrational Behavior in Milling Machines by Sensor Fusion. Procedia CIRP, 2015. 33: 239-244.

[24] Y. Altintas, Manufacturing Automation: Metal Cutting Mechanics, Machine Tool Vibrations, and CNC Design, Cambridge University Press, Cambridge, 2012.

[25] C. Wang, X. Zhang, B. Qiao, H. Cao, X. Chen. Dynamic Force Identification in Peripheral Milling Based on CGLS Using Filtered Acceleration Signals and Averaged Transfer Functions. ASME. Journal of Manufacturing 
Science and Engineering, 2019, 141(6): 064501. https://doi.org/10.1115/1.4043362

[26] T.L. Schmitz, K.S. Smith, Milling Dynamics. Springer, Boston, MA, 2009.

[27] M. Jalili, J. Hesabi, M. Abootorabi. Simulation of forced vibration in milling process considering gyroscopic moment and rotary inertia. International Journal of Advanced Manufacturing Technology, 2017, 89(9-12): 28212836. 